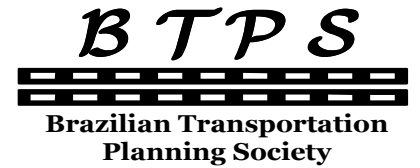

Planning Society
Journal of Transport Literature

Vol. 8, n. 1, pp. 125-158, Jan. 2014

Research Directory
JTL | RELIT

www.transport-literature.org ISSN 2238-1031

\title{
Sistema de apoio à decisão baseado em planilha eletrônica para otimização da programação de entrega de concreto pronto
}

[A spreadsheet-based decision support system for optimizing the schedule of ready-mix concrete]

\author{
Claudio Barbieri da Cunha*, Clicia Soriano Cortes \\ Universidade de São Paulo - Brasil
}

Submitted 7 Dec 2012; received in revised form 14 Jan 2013; accepted 21 Jan 2013

\begin{abstract}
Resumo
Este artigo trata de um sistema de apoio à decisão (SAD) baseado em planilha eletrônica para o problema de programação das entregas de concreto produzido em centrais dosadoras, adequado à realidade brasileira. Tal programação engloba as decisões de qual central deverá atender cada cliente e em qual horário cada veículo de entrega deverá ser carregado nessa central, de forma a maximizar a receita marginal total do sistema. São consideradas restrições de capacidade de carregamento de veículos por central, disponibilidade da frota e garantia de atendimento, por uma única central, de todos os pedidos de cada cliente. A fim de resolver esse problema de otimização de maneira rápida e eficiente, é proposto um modelo de programação matemática baseado em uma rede espaço-tempo. 0 SAD em ambiente de planilha eletrônica, inédito na literatura, possibilita a sua utilização em uma empresa concreteira que opera diversas centrais dosadoras de concreto de maneira fácil e direta, por usuários sem conhecimentos de pesquisa operacional, sendo portanto adequado para empresas que não tem porte ou não estão preparadas para investir em sistemas corporativos de apoio à programação.
\end{abstract}

Palavras-Chave: programação de entrega, concreto dosado em central, rede espaço-tempo.

\begin{abstract}
This paper addresses a spreadsheet-based decision support system (DSS) for the problem of scheduling the delivery of ready mix concrete produced in concrete batch plants or centers taking into consideration the Brazilian reality. Such scheduling comprises decisions of what facility should serve each customer and what time each delivery vehicle should be loaded, so as to maximize the total marginal revenue of the system. Vehicle loading capacity constraints per center, fleet availability and ensuring that each client's orders are fulfilled by a single plant are considered. In order to solve this optimization problem efficiently we propose a mathematical programming model based on a time-space network. The spreadsheet-based DSS, novel in the literature, allows a concrete company which operates several concrete batch plants company to schedule its daily operations in an easy and straightforward manner, by users with no background in operations research, thus making it especially suitable for companies that are not ready or whose size does not allow the investment in a corporate system to aid the scheduling.
\end{abstract}

Key words: delivery scheduling, ready mix concrete, space-time network.

*Email: cbcunha@usp.br.

\section{Recommended Citation}

Cunha, C. B. and Cortes, C. S. (2014) Sistema de apoio à decisão baseado em planilha eletrônica para otimização da programação de entrega de concreto pronto. Journal of Transport Literature, vol. 8, n. 1, pp. 125-158.

- JTL/RELIT is a fully electronic, peer-reviewed, open access, international journal focused on emerging transport markets and published by BPTS - Brazilian Transport Planning Society. Website www.transport-literature.org. ISSN 2238-1031.

This paper is downloadable at www.transport-literature.org/open-access. 


\section{Introdução}

Este artigo trata do problema de programação diária de entrega do concreto a partir de centrais dosadoras de uma mesma empresa, a qual engloba decisões de qual central dosadora deverá atender cada cliente e em qual horário cada veículo de entrega deverá ser carregado nessa central, respeitando limitações de frota e de capacidade de carregamento, de forma a maximizar a margem de contribuição total do sistema.

Com base em entrevistas e visitas a empresas brasileiras do setor, foi possível propor um modelo matemático cuja formulação baseia-se na representação do problema através de uma rede espaço-tempo, possibilitando considerar as restrições mais relevantes do problema, incluindo a situação em que a demanda de concreto é maior que a capacidade de atendimento, o que leva o modelo a selecionar os pedidos levando em conta não só a receita auferida, como também os custos variáveis de produção e de entrega, que podem variar de usina para usina, além de cliente para cliente.

Uma rede espaço-tempo, como o próprio nome já sugere, é uma representação gráfica de eventos que ocorrem no espaço ao longo do tempo. Cada nó da rede representa um local/atividade (central ou pedido de cliente), em um dado instante de tempo, dentro do horizonte de planejamento escolhido; os arcos representam deslocamentos dos veículos ou atividades de carregamento (na central) ou entrega do concreto (em algum cliente). Essa abordagem, além de facilitar a modelagem matemática do problema, permite que a solução ótima seja obtida mais rapidamente, tendo em vista a estrutura intrínseca resultante da formulação matemática resultante (Ahuja et al., 1993).

O modelo foi implementado em ambiente de planilha eletrônica do tipo Excel, de modo a compor um sistema de apoio à decisão (SAD), em linguagem VBA ("Visual Basic for Applications"), de modo a proporcionar uma interface amigável que facilita a entrada de dados e a compreensão dos resultados finais pelos usuários do modelo, os quais não necessitam ter conhecimento prévio de pesquisa operacional ou modelagem matemática, uma vez que a construção do modelo matemático de otimização é totalmente automatizada e transparente. Isto pode ser particularmente interessante e útil principalmente para empresas de menor porte, que 
podem não dispor de recursos nem estarem preparadas para investir, operar e manter um sistema corporativo. Ou ainda para empresas que já disponham de algum sistema corporativo, porém que não seja viável de ser implantado em regiões com centrais menores, como é o caso de uma grande empresa do setor no Brasil em que o modelo proposto foi aplicado a um problema real,.

O concreto é um dos materiais mais importantes dos componentes estruturais das obras civis, e sua utilização abrange desde obras de grande porte (tais como, por exemplo, obras de arte como pontes e viadutos, obras marítimas, etc.), a construção de edificações (principalmente prédios residenciais ou comerciais) até a manufatura de pequenas peças como pré-moldados de pequena escala.

A sua produção pode ser realizada no próprio canteiro de obras (normalmente quando utilizado em pequena escala) ou em empresas prestadoras de serviços de concretagem - as centrais dosadoras de concreto que utilizam caminhões específicos (chamados caminhões betoneiras) para entregar o produto ao cliente.

Segundo estudos do Sindicato Nacional da Indústria de Cimentos (SNIC, 2011), o mercado de cimento e concreto apresenta crescente expansão, o consumo aparente de cimento terminou o ano de 2011 com 65 milhões de toneladas, representando um aumento de 8,3\% com relação a 2010. O consumo per capita alcançou $333 \mathrm{~kg} / \mathrm{hab} / \mathrm{ano}$, a maior marca de toda a história. O programa de expansão de capacidade instalada continuou, permitindo à indústria elevar sua produção em 8,4\%, chegando ao patamar de 64 milhões de toneladas. Ainda foram importadas 1 milhão de toneladas para abastecer pontualmente o mercado. Tendo em vista o cenário de crescimento do setor da construção civil, a tendência é de diminuição da ociosidade das centrais dosadoras, o que leva à necessidade de aumentar o seu nível de eficiência operacional, da etapa da programação até as efetiva entregas, a fim de assegurar a melhor utilização da capacidade instalada e do retorno dos investimentos.

Pode-se dizer que o concreto comporta-se como uma "commodity". Sendo assim, não existe grande diferenciação do produto entre empresas concorrentes. Portanto, o custo e o nível de serviço são diferenciais competitivos importantes, além da localização das centrais dosadoras, uma vez que a mesmo limita o raio máximo de atendimento, dada a perecibilidade do concreto devido ao seu endurecimento. O nível de serviço implica cumprir horários e entregas programadas. Nesse contexto, uma ferramenta que possa realizar reprogramações periódicas e 
garantir o atendimento nos horários solicitados torna-se um diferencial competitivo para empresas produtoras de concreto.

Programar e realizar entregas de concreto de um modo eficiente para os clientes é desafiador. Isso se deve principalmente ao fato dos pedidos apresentarem, majoritariamente, quantidades maiores do que a capacidade de um caminhão; e também às propriedades do concreto, um produto altamente perecível, que endurece em até três horas depois de produzido. O problema torna-se ainda mais complexo quando se considera que todos os pedidos de um mesmo cliente, para um mesmo local, devem ser atendidos pela mesma central, a fim de garantir a homogeneidade do produto entregue.

O restante deste artigo está organizado da seguinte forma: a revisão bibliográfica é apresentada na Seção 1. A Seção 2 descreve a modelagem com a formulação matemática proposta para o problema cuja implementação em ambiente de planilha é demonstrada na Seção 3. Os cenários considerados para a validação do modelo são apresentados na Seção 4, enquanto que um problema real de programação de entrega de concreto é apresentado na Seção 5. Finalmente, as considerações finais, incluindo as recomendações para a continuidade dessa pesquisa, são apresentadas na última seção.

\section{A Programação da Produção e Entrega de Concreto na Literatura}

Apesar da pequena quantidade de trabalhos desenvolvidos até hoje sobre o tema, o problema tem sido abordado, nos últimos anos, com diferentes abordagens, modelagens e métodos de solução. Em um dos primeiros trabalhos sobre a logística de entrega do concreto, Tommelein e Li (1999) tratam do conceito de produção just-in-time, abordando o caso específico de entrega do concreto como um exemplo desse tipo de processo produtivo. Em contraste com as outras publicações analisadas, essa não tem um foco de modelagem; compreende uma abordagem conceitual do processo, apresentando um resumo das características que permeiam o problema de produção, carregamento e entrega do concreto.

O trabalho de Zayed e Halpin (2001) é um dos primeiros encontrados na literatura que abordou o tema da programação de produção de concreto. Foi aplicado um modelo de simulação nas operações de programação da produção e analisadas soluções alternativas e gerenciamento 
(alocação) de recursos através de um sistema de simulação chamado Microcyclone. O foco foi na produção do material, tendo sido analisadas condições gerais de custos para a determinação do melhor momento de compra da matéria-prima para a produção do material. Por outro lado, não consideraram o processo de distribuição do concreto, algo que diferencia em relação a este trabalho. Os resultados gerados foram utilizados para a definição das melhores soluções de compra de insumos que pudessem diminuir o tempo de produção do concreto e o abastecimento dos caminhões.

Wang et al. (2001) propuseram um modelo de simulação estocástica (Monte Carlo) que utiliza uma planilha de dados conjuntamente com o software @Risk para analisar o efeito do intervalo entre chegadas dos caminhões na produtividade das centrais dosadoras de concreto na cidade de Singapura. Com o objetivo de minimizar os custos, determinaram o melhor intervalo entre chegadas de caminhões a fim de reduzir as filas de caminhões dentro das centrais, maximizando a utilização de recursos (como bombas de aplicação de concreto) utilizados no processo de entrega.

Durbin (2003) e Durbin e Hoffman (2008) elaboraram um sistema de suporte a decisão para auxiliar a equipe de planejamento e programação de uma empresa nas decisões envolvidas com as entregas do concreto. Tal sistema é capaz de analisar milhares de alternativas para o atendimento da demanda considerando particularidades do negócio tais como perecibilidade do material, overbooking (i.e., aceitação de pedidos e agendamento de entregas acima da capacidade dos recursos disponíveis em decorrência de cancelamentos de pedidos de última hora que usualmente ocorrem), necessidade de entregas sincronizadas e a capacidade dos caminhões. Chamando de "a dança dos caminhões de 30 toneladas" (do inglês, "the dance of the thirty-ton trucks") os autores se inspiraram em um problema real para desenvolver a pesquisa. A Virginia Concrete, empresa norte americana que possui um grupo de centrais dosadoras de concreto, solicitou ajuda dos autores no problema de filas de caminhões existentes tanto dentro de cada central como nos canteiros de obras de seus clientes. Ao estudar o problema, os autores perceberam que o mesmo não dizia respeito apenas às filas no carregamento e descarregamento do material, e sim à logística de atendimento dos pedidos, incluindo aceitação dos pedidos, planejamento de entrega e despacho dos caminhões pelas centrais. Assim, foi proposto um sistema de suporte a decisão que hoje ainda é utilizado com sucesso por essa empresa. Essa ferramenta é capaz de definir os pedidos que podem ser aceitos, o horário de chegada dos 
motoristas dos caminhões, o horário programado para o carregamento e a entrega dos pedidos e a programação de produção de cada central dosadora de concreto.

Anson et al. (2003) estudaram o caso da indústria de concreto com o foco na previsão da demanda. Foi desenvolvido um modelo de simulação de previsão de demanda e planejamento de produção para uma central dosadora de concreto em Hong Kong. O objetivo foi estimar uma demanda de concreto para cada central durante um dia típico de vendas.

Já Matsatsinis (2004) tratou do problema de otimização dos roteiros de entrega de bombas de concreto, que foi modelado como uma roteirização de veículos com frota heterogênea, múltiplos depósitos e janelas de entregas. No problema tratado, as bombas necessitam ser roteirizadas e entregues concomitantemente com as entregas de concreto, de tal forma que no momento da entrega do concreto, a bomba estivesse disponível para utilização.

Feng e Wu (2000) e Feng et al. (2004), trataram de um problema de entrega de concreto com uma única central em Hong Kong. O objetivo desse modelo foi minimizar o tempo de espera no atendimento de um cliente (evitando que o caminhão chegue antes do horário programado), de tal forma que, esse tempo possa ser aproveitado para satisfazer as necessidades de entregas de outras obras. Para isso, foi construído um modelo baseado em algoritmos genéticos.

Yan et al. (2007) modelaram o problema de programação de entrega do concreto como um problema de fluxo em rede em uma rede espaço-tempo. Objetivando a minimização dos custos, consideram como restrições a demanda dos clientes, o tamanho da frota e a capacidade de carregamento de cada central. Também consideram uma restrição de distância entre centrais e clientes para evitar o endurecimento do material no caminhão. Adicionalmente, também levam em consideração uma restrição de horas extras para diminuir o tempo de serviço dos caminhões e centrais. Esse modelo foi aplicado a um caso real de uma concreteira em Taiwan.

Em síntese, a maioria dos trabalhos encontrados na literatura trataram de aspectos ligados à programação da produção ou previsão de demanda nas centrais, ou da programação e operação da frota dos veículos. Inspirado em Durbin (2003) e Durbin e Hoffman (2008), e embasado em um amplo levantamento junto a empresas brasileiras do setor, foi possível propor no presente trabalho um modelo ajustado para a realidade brasileira, levando em consideração peculiaridades como a necessidade de avaliar a aceitação de pedidos por problemas de capacidade com base 
numa estimativa não só da receita bruta, mas também dos custos de atendimento, e que pudesse ser utilizado de maneira rápida e fácil pelas empresas, sem necessidade de usualmente longo período de desenvolvimento de algum sistema mais formal, que necessita atender diversos requisitos usuais das áreas de tecnologia da informação das empresas.

\section{Formulação Matemática}

O problema de programação de carregamento e entrega de concreto produzido em centrais dosadoras consiste em determinar qual central dosadora atenderá cada um dos clientes que solicitaram o produto, e em que horário será realizado o carregamento do(s) veículo(s) na central, de modo a maximizar a margem de contribuição total do sistema.

Conforme comentado anteriormente na Seção 1, os modelos encontrados na literatura tratam em geral da questão de como definir uma programação que minimize o custo total, ou maximize a receita total do conjunto de centrais. No entanto, a escolha da maximização da margem de contribuição (também designada como receita marginal, e expressa como a diferença entre a receita bruta e os custos variáveis de fornecimento do produto) na função objetivo foi considerada uma forma diferente para se resolver o caso em questão. Vale ressaltar que no caso de todos os pedidos poderem ser atendidos, maximizar a margem de contribuição significa o mesmo que minimizar o custo variável total, já que a receita (expressa como o produto entre a quantidade entregue em toneladas e o preço unitário por tonelada) será sempre a mesma, uma vez que o preço do produto não depende da central que o fornece. Por outro lado, caso a demanda supere a capacidade de atendimento, a consideração dos custos variáveis, e consequentemente a margem de contribuição, é essencial a fim de selecionar quais pedidos devem ser atendidos de modo a assegurar que a rentabilidade da empresa (e não a receita bruta) seja maximizada, conforme modelo proposto mais adiante na Seção 3.2. A não consideração dos custos fixos é uma prática que ocorre no setor (ver, por exemplo, Pandolfi, 1999) tendo em vista a dificuldade de rateio dos mesmos, que dependendo da maneira como for feita, pode acarretar distorções. 
Independente de haver ou não capacidade disponível para atender todos os pedidos são consideradas, no presente trabalho as seguintes restrições:

- capacidade de abastecimento de caminhões nas centrais, usualmente expressa em veículos por hora;

- disponibilidade da frota de caminhões betoneiras em cada central (veículos);

- overbooking máximo permitido no sistema, usualmente expresso como uma porcentagem (\%) da capacidade de abastecimento;

- atendimento de todos os pedidos de um determinado cliente por uma única central, a fim de garantir a homogeneidade da carga, desde que sejam todos para a mesma obra.

A fim de resolver o problema de programação de carregamento e entrega do concreto é proposta uma modelagem como um problema de fluxo em rede, em uma rede espaço-tempo ("space-time network flow problem"), de maneira similar ao trabalho de Durbin (2003) e Durbin e Hoffman (2008). Este tipo de modelagem possibilita considerar as restrições mais relevantes do problema. Para maiores detalhes sobre modelos de fluxo em rede recomenda-se, por exemplo, a obra de Ahuja et al. (1993).

A rede espaço-tempo corresponde a um grafo que permite representar eventos que ocorrem no espaço em instantes ou períodos de tempo pré-determinados. Mais especificamente, cada nó da rede representa um local, no caso uma central dosadora ou um local de entrega de um cliente, em um dado instante de tempo.

Considera-se que o tempo seja discretizado em períodos padrão, usualmente de 15, 30 minutos, até no máximo uma hora. O horizonte de programação usual é de um dia, uma vez que a programação é normalmente feita diariamente, de forma independente, sem considerar mais de um dia, de acordo com a prática das empresas do setor. De qualquer forma, a formulação é suficientemente genérica a ponto de possibilitar considerar um horizonte de programação superior a um dia. 
Formalmente, seja $G=(N, A)$ a rede espaço-tempo que representa o problema, onde $N$ e $A$ indicam os conjuntos de nós e arcos, respectivamente. Um eixo horizontal pode representa os períodos de tempo dentro do horizonte de planejamento, enquanto um eixo vertical indica a dimensão espacial dos deslocamentos entre centrais e clientes. Seja $T$ o horizonte de tempo considerado e $T=(1,2,3, \ldots,|T|)$ cada um dos períodos de tempo dentro desse intervalo. Seja $J=$ $(1,2,3, \ldots,|J|)$ o conjunto de clientes que requerem entrega de concreto e $I=(1,2,3, \ldots,|I|)$ o conjunto de centrais dosadoras de onde podem partir os caminhões betoneiras para entrega do concreto para os clientes $j \in J$.

A cada cliente $j \in J$ está associado um conjunto de pedidos de entregas $P_{j}=\left(1,2,3, \ldots,\left|P_{j}\right|\right)$. Para cada pedido $p \in P_{j}$ é conhecida a demanda de concreto $b_{j}^{p}$ (em número de caminhões necessários) a ser entregue, o horário solicitado para a entrega $h_{j}^{p}$ e o tempo total de descarregamento $t d_{j}^{p}$. As demandas $b_{j}^{p}$ são conhecidas a priori e não mudam, mesmo se a demanda for superior à capacidade de atendimento; nesse caso, em consonância com a prática do setor, a decisão está relacionada apenas ao atendimento ou não do pedido, e não à quantidade que pode efetivamente ser entregue.

A cada central dosadora de concreto $i \in I$ está associada uma capacidade de carregamento $C_{i}$ (em caminhões por unidade de tempo), assim como a frota de caminhões próprios $D_{i}$ que estão disponíveis no início do período de planejamento. Considera-se que a capacidade de carregamento $C_{i}$ de cada central não varia durante o dia, pois os recursos para carregamento em cada central (postos de carga, bombas específicas, etc.) normalmente não sofrem alteração ao longo do dia. Adicionalmente, a quantidade de caminhões disponíveis para carregamento a cada período de tempo considerado só varia de acordo com as saídas e entradas dos caminhões pertencentes a central em questão, visto que, na prática não são feitas realocações de caminhões entre centrais, tendo em vista as dificuldades de gestão da frota e de pessoal, de acordo com levantamentos junto a empresas do setor. Assim, um caminhão deve sempre retornar à central de onde partiu, mesmo que o mesmo possa eventualmente ser necessário em outra central. 
É conhecido também o tempo de viagem (ou deslocamento) $t_{i j}$ do caminhão betoneira no percurso entre cada central $i \in I$ e cada cliente $j \in J$ e vice-versa. Assume-se que os tempos de deslocamento dos veículos independam dos mesmos estarem ou não carregados, e que o itinerário de ida é o mesmo que o de volta. Portanto, o tempo de viagem de ida até um cliente, a partir de uma central, e de retorno, são iguais. Seria possível considerar tempos distintos sem a necessidade de nenhuma alteração adicional na representação da rede, porém, na prática, a velocidade do caminhão é condicionada mais pelas condições de trânsito do que pelo fato do caminhão estar ou não carregado. Assume-se ainda que a diferença entre o consumo de combustível do veículo carregado e vazio seja desprezível, embora o modelo seja genérico o suficiente para permitir variações tanto das velocidades quanto dos custos variáveis nos percursos carregado e vazio.

Conforme observado nas visitas realizadas, pode-se assumir frota de caminhões homogênea em termos de capacidade, desempenho e custo. O presente trabalho não considera necessidades especiais de alguns pedidos como bombas de descarregamento, equipamentos especiais, etc.

A Figura 1 exemplifica uma rede espaço-tempo com duas centrais e cinco pedidos de um mesmo cliente. As setas em linhas contínuas representam os arcos de viagem dos veículos carregados para atendimento dos pedidos a partir das centrais 1 e 2. Note-se que, nesse exemplo, o atendimento de cada um dos cinco pedidos pode ser realizado por qualquer uma das duas centrais. De forma análoga, os arcos de traços pontilhados representam os arcos de viagem de retorno dos veículos vazios, às centrais 1 e 2, após as entregas nos clientes.

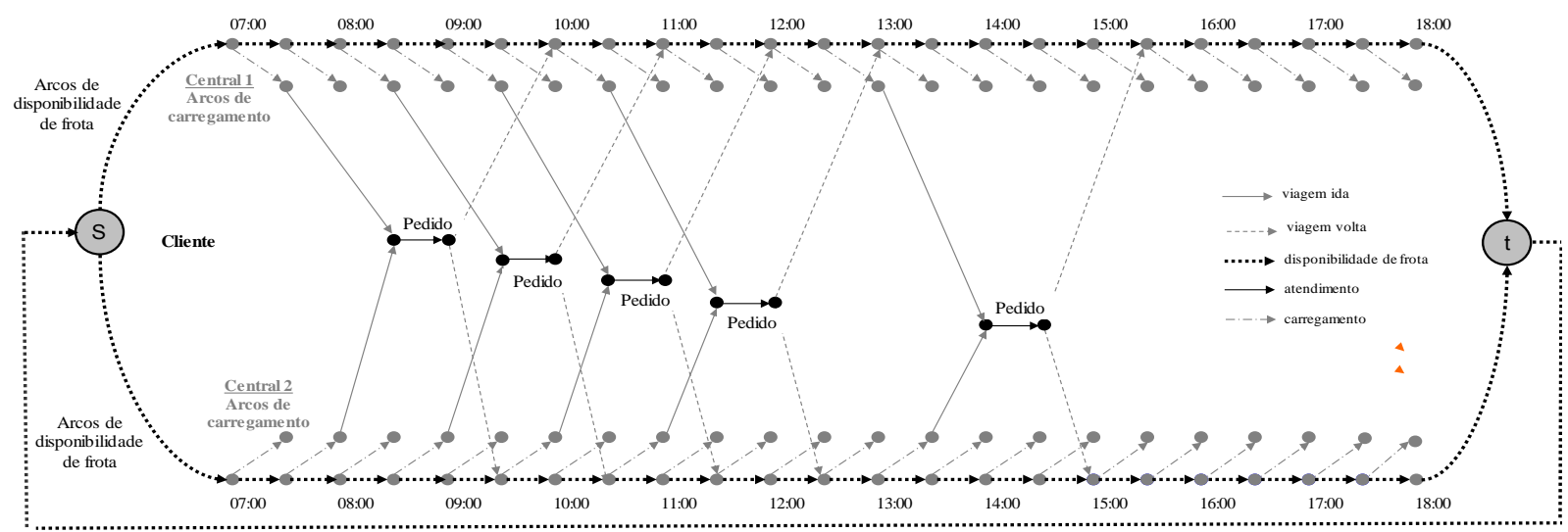

Figura 1 - Rede espaço-tempo que representa exemplo do problema de programação de entrega de concreto 
O intervalo de tempo é considerado igual a 30 minutos. A fim de ilustrar a forma como a rede espaço-tempo é construída, são apresentados na Tabela 1 os dados de entrada para os cinco pedidos da Figura 1, bem como cálculos de tempo que são utilizados para a construção de rede que representa o problema.

Tabela 1 - Cálculo dos horários de carregamento, saída da central e retorno de caminhões conforme exemplo ilustrado na Figura 1

\begin{tabular}{|c|c|c|}
\hline Pedido & $\begin{array}{c}\text { Horário } \\
\text { solicitado } \\
\text { para } \\
\text { recebimento } \\
\text { do material } \\
\boldsymbol{h}^{p}\end{array}$ & $\begin{array}{c}\text { Tempo de } \\
\text { descarregamento } \\
\text { no cliente } \\
\boldsymbol{t d}^{p}\end{array}$ \\
\hline Pedido 1 & $08: 30$ & $00: 30$ \\
\hline Pedido 2 & $09: 30$ & $00: 30$ \\
\hline Pedido 3 & $10: 30$ & $00: 30$ \\
\hline Pedido 4 & $11: 30$ & $00: 30$ \\
\hline Pedido 5 & $14: 00$ & $00: 30$ \\
\hline
\end{tabular}

\begin{tabular}{|c|c|c|c|}
\hline \multicolumn{3}{|c|}{ Atendimento realizado pela Central 1 } \\
\hline $\begin{array}{c}\text { Tempo de } \\
\text { viagem entre } \\
\text { a central e o } \\
\text { cliente } \\
t_{i j}\end{array}$ & $\begin{array}{c}\text { Horário de } \\
\text { saída da } \\
\text { central }\end{array}$ & $\begin{array}{c}\text { Horário de } \\
\text { carregamento }\end{array}$ & $\begin{array}{c}\text { Horário de } \\
\text { retorno a } \\
\text { central }\end{array}$ \\
\hline $01: 00$ & $07: 30$ & $07: 00$ & $10: 00$ \\
\hline $01: 00$ & $08: 30$ & $08: 00$ & $11: 00$ \\
\hline $01: 00$ & $09: 30$ & $09: 00$ & $12: 00$ \\
\hline $01: 00$ & $10: 30$ & $10: 00$ & $13: 00$ \\
\hline $01: 00$ & $13: 00$ & $12: 30$ & $15: 30$ \\
\hline
\end{tabular}

\begin{tabular}{|c|c|c|c|}
\hline \multicolumn{3}{|c|}{ Atendimento realizado pela Central 2 } \\
\hline $\begin{array}{c}\text { Tempo de } \\
\text { viagem entre } \\
\text { a central e o } \\
\text { cliente } \\
t_{i j}\end{array}$ & $\begin{array}{c}\text { Horário de } \\
\text { saída da } \\
\text { central }\end{array}$ & carregamento & $\begin{array}{c}\text { Horário de } \\
\text { Horário de } \\
\text { retorno a } \\
\text { central }\end{array}$ \\
\hline $00: 30$ & $08: 00$ & $07: 30$ & $09: 30$ \\
\hline $00: 30$ & $09: 00$ & $08: 30$ & $10: 30$ \\
\hline $00: 30$ & $10: 00$ & $09: 30$ & $11: 30$ \\
\hline $00: 30$ & $11: 00$ & $10: 30$ & $12: 30$ \\
\hline $00: 30$ & $13: 30$ & $13: 00$ & $15: 00$ \\
\hline
\end{tabular}

Para cada pedido, o horário de partida de cada central é calculado subtraindo-se o respectivo tempo de viagem do horário de recebimento do material, ou seja, $\left(h_{j}^{p}-t_{i j}\right)$. Já o horário de carregamento é determinado subtraindo-se o tempo de carregamento do horário de saída da central. O horário de retorno do veículo à central é obtido somando-se o horário de recebimento do material $\left(h_{j}^{p}\right)$, o tempo de descarregamento no cliente $\left(t d_{j}^{p}\right)$ e o tempo de viagem $\left(t_{i j}\right)$.

Em linhas gerais, os nós da rede representam locais (centrais ou clientes) em determinado período (ou horário). Por exemplo, os instantes de início e de fim da entrega de concreto de um dado cliente $j \in J$ de forma a atender um dado pedido $p \in P_{j}$ correspondem a dois nós $k, l \in N$. Da mesma forma, os $\operatorname{arcos}(k, l) \in A$ que interligam dois nós quaisquer $k, l \in N$ dessa rede representam as diferentes atividades que compreendem a entrega de concreto: viagem de ida ou de volta entre centrais e clientes, carregamento dos caminhões, atendimento dos pedidos dos clientes e finalmente, arcos de disponibilidade de frota. Assim, a cada $\operatorname{arco}(k, l) \in A$ está associado um fluxo de caminhões, entre seus nós de origem e destino, correspondente a cada um dos eventos englobados pela movimentação.

O conjunto dos $\operatorname{arcos} A$ da rede $G=(N, A)$ pode ser subdividido em diversos subconjuntos, com a finalidade de descrever como os mesmos são construídos. 
Seja $\operatorname{ArcViag}_{\text {ida }} \subset A$ o conjunto dos arcos de viagem de ida $(k, l) \in A$ que ligam as centrais aos clientes representando, dessa forma, a possibilidade de atendimento de um pedido de um cliente $i$ $\in I$ por uma central $j \in J$. Um arco de viagem $(k, l) \in \operatorname{ArcViag}_{\text {ida }}$ tem a sua extremidade de origem em uma central no período $t_{1} \in T$ correspondente ao horário em que o caminhão está disponível e pronto para partir após ser carregado. Já a extremidade de destino $l$ do arco de viagem $(k, l)$ indica o local onde o cliente $j$ do pedido $p$ se situa no período $t_{2}=t_{1}+t_{i j}$ correspondente ao horário solicitado para a entrega.

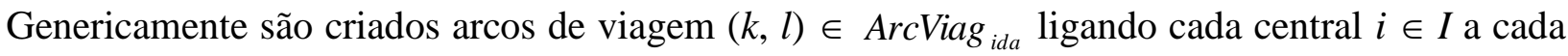
cliente $j \in J$, iniciando e terminando nos intervalos de tempo de tal forma a assegurar que os horários de entrega nos clientes sejam respeitados, tendo em vista os tempos de viagem $t_{i j}$ entre cada central $i \in I$ e cada cliente $j \in J$. Adicionalmente, avalia-se também se é possível atender um cliente $j$ a partir de uma central $i$ considerando a perecibilidade do concreto face ao tempo de viagem $t_{i j}$. Em outras palavras, se um cliente $j$ estiver muito distante de uma central $i$, de modo que o tempo de viagem $t_{i j}$ seja muito elevado face ao tempo até o endurecimento do concreto, o $\operatorname{arco}(k, l)$ não é criado.

Define-se ainda o conjunto ArcCliente $_{j}$ como o conjunto de todos os $\operatorname{arcos}(k, l) \in$ ArcViag $_{\text {ida }}$ que representam todas as possibilidades de atendimento de cada pedido $p \in P_{j}$ do cliente $j \in J$ por alguma central $i \in I$. Por exemplo, para o pedido 1 da Figura 1, cujos dados estão na Tabela 1, o horário solicitado pelo cliente para recebimento do concreto é 8:30. Caso esse pedido seja atendido pela central 1 o caminhão deve deixar a central às 7:30 para garantir o atendimento do pedido no horário solicitado, tendo em vista que o tempo de viagem é de 1 hora conforme indicado na Tabela 1. Com isso, tem-se um arco $(k, l) \in A$ de viagem ligando o nó correspondente à central 1 no período 7:30 com nó correspondente ao cliente no período 8:30. Analogamente, para atendimento do pedido 1 pela central 2 é criado o arco de viagem ligando o período 8:00 da central 2 com o período 8:30 do cliente, uma vez que o tempo de viagem é de 30min.

O conjunto ArcViag ${ }_{\text {volta }}$ compreende todos os arcos de viagem de volta que representam, como o próprio nome já diz, os retornos dos caminhões para as centrais dosadoras de concreto após o atendimento dos pedidos. Para a construção dos arcos de viagem de volta considera-se tanto o 
tempo de descarregamento no cliente como o tempo de viagem entre o cliente e a central. Exemplificando, são criados dois arcos de retorno após atendimento do pedido 1, ambos partindo no horário de 9:00, após o término do descarregamento no cliente, e retornando às centrais 1 e 2 às 10:00 e 9:30, respectivamente.

Já o conjunto de arcos de atendimento dos pedidos ArcAtend representa o atendimento de cada um dos pedidos. Como mencionado anteriormente, ambas as extremidades do arco correspondem ao local onde o cliente que fez o pedido está localizado. O nó de origem indica o período $t_{1} \in T$ solicitado pelo cliente para recebimento do material enquanto que, o nó de destino do arco indica o horário de termino $t_{2} \in T$ do descarregamento no cliente, onde $t_{2}=t_{1}+$ $t d^{p}$. No exemplo da Figura 1 para o pedido 1, o horário solicitado pelo cliente para recebimento do concreto é 8:30. Como o tempo de descarregamento no cliente é de 30min (conforme a Tabela 1), haverá um arco de descarregamento no cliente com a sua origem no período 8:30 e destino no período 9:00 do mesmo cliente.

O conjunto ArcCarreg corresponde aos arcos de carregamento que representam o carregamento de caminhões para atendimento de uma demanda específica de um pedido de um cliente. Esses arcos de carregamento têm as suas extremidades de origem em cada central no período $t \in T$ em que o caminhão deve iniciar o processo de carregamento para atender ao horário solicitado pelo cliente. Por outro lado, o nó de destino destes arcos de carregamento representa, dentro da mesma central, um período de tempo $t \in T$ que é determinado com base no tempo de carregamento estimado de cada central dosadora de concreto.

Por fim, o grupo de arcos de disponibilidade de frota ArcDisp indica os caminhões que estão disponíveis em cada central $i \in I$ e em cada período de tempo $t \in T$ aguardando o carregamento do concreto. $\mathrm{O}$ conjunto de arcos de disponibilidade que fazem a conexão entre um período de tempo e o próximo período de tempo de uma mesma central, representam a possibilidade do caminhão permanecer dentro da mesma central aguardando o seu carregamento para atendimento de um pedido de um cliente.

A cada arco de viagem $(k, l) \in$ ArcViag está associado um valor de receita marginal $R M a r g_{k l}$ por caminhão, correspondente ao atendimento de um pedido $p \in P_{j}$ de um cliente $j \in J$ a partir de uma central $i \in I$. Para os demais $\operatorname{arcos} \operatorname{RMarg}_{k l}=0$. 
Definem-se ainda o limitante inferior $L_{k l}$ e o limitante superior $U_{k l}$ para o fluxo em cada um dos $\operatorname{arcos}(k, l) \in A$. Para os $\operatorname{arcos}(k, l) \in$ ArcAtend, $L_{k l}=U_{k l}=b^{p}$, de tal modo a obrigar que o fluxo no $\operatorname{arco}(k, l)$ corresponda ao atendimento integral do pedido $p \in P_{j}$ de um cliente $j \in J$ ao qual corresponde o $\operatorname{arco}(k, l)$. Já para os arcos de carregamento $(k, l) \in \operatorname{ArcCarreg,} L_{k l}=0$ e $U_{k l}=C_{i}$, de tal modo que o número de caminhões sendo carregado em cada período de tempo $t \in T$ não ultrapasse a capacidade de carregamento de cada central $i \in I$ à qual corresponde o arco $(k, l)$. Analogamente, para os arcos de disponibilidade de frota $(k, l) \in \operatorname{ArcDisp}$, assume-se que $L_{k l}=0$ e $U_{k l}=D_{i}$. Para os demais $\operatorname{arcos} L_{k l}=0$ e $U_{k l}=\infty$. A fim de facilitar a modelagem matemática do problema, assume-se rede fechada, em que há conservação de fluxo, sendo assim necessário criarem-se um nó fonte fictício $s \in N$, um nó sorvedouro fictício $t \in N$ e um arco de ligação $(t, s)$ $\in A$. Estes nós não têm significado prático, pois como o próprio nome já diz, são fíctícios, ou seja, não existem na realidade, e tem por finalidade assegurar as condições de conservação de fluxo.

Para o exemplo da Figura 1 os seguintes tipos de arcos (com os seguintes atributos) poderiam ser definidos conforme a Figura 2 e a Tabela 2.

\subsection{Modelo Matemático para o caso em que a demanda não supera a capacidade de atendimento}

Definem-se as seguintes variáveis de decisão:

$x_{k l}=$ fluxo de caminhões no $\operatorname{arco}(k, l) \in A$

$y_{i j}=1 ;$ se o cliente $j$ é atendido a partir da central $i$;

$=0$; caso contrário.

Com base nas definições anteriores, o modelo matemático pode ser formulado como: 
Maximizar $=\sum_{(k, l) \in A} \operatorname{Marg}_{k l} x_{k l}$

Sujeito a:

$$
\begin{array}{ll}
L_{k l} \leq x_{k l} \leq U_{k l} & \forall(k, l) \in A \\
x_{k l} \leq y_{i j} U_{k l} & \forall(k, l) \in \text { ArcCliente }_{j}, \forall i \in I \text { e } \forall j \in J \\
\sum_{(I, k) \in A} x_{l k-\sum_{(k, l) \in A} x_{k l}=0} & \forall k \in N \\
\sum_{i} y_{i j}=1 & \forall j \in J
\end{array}
$$

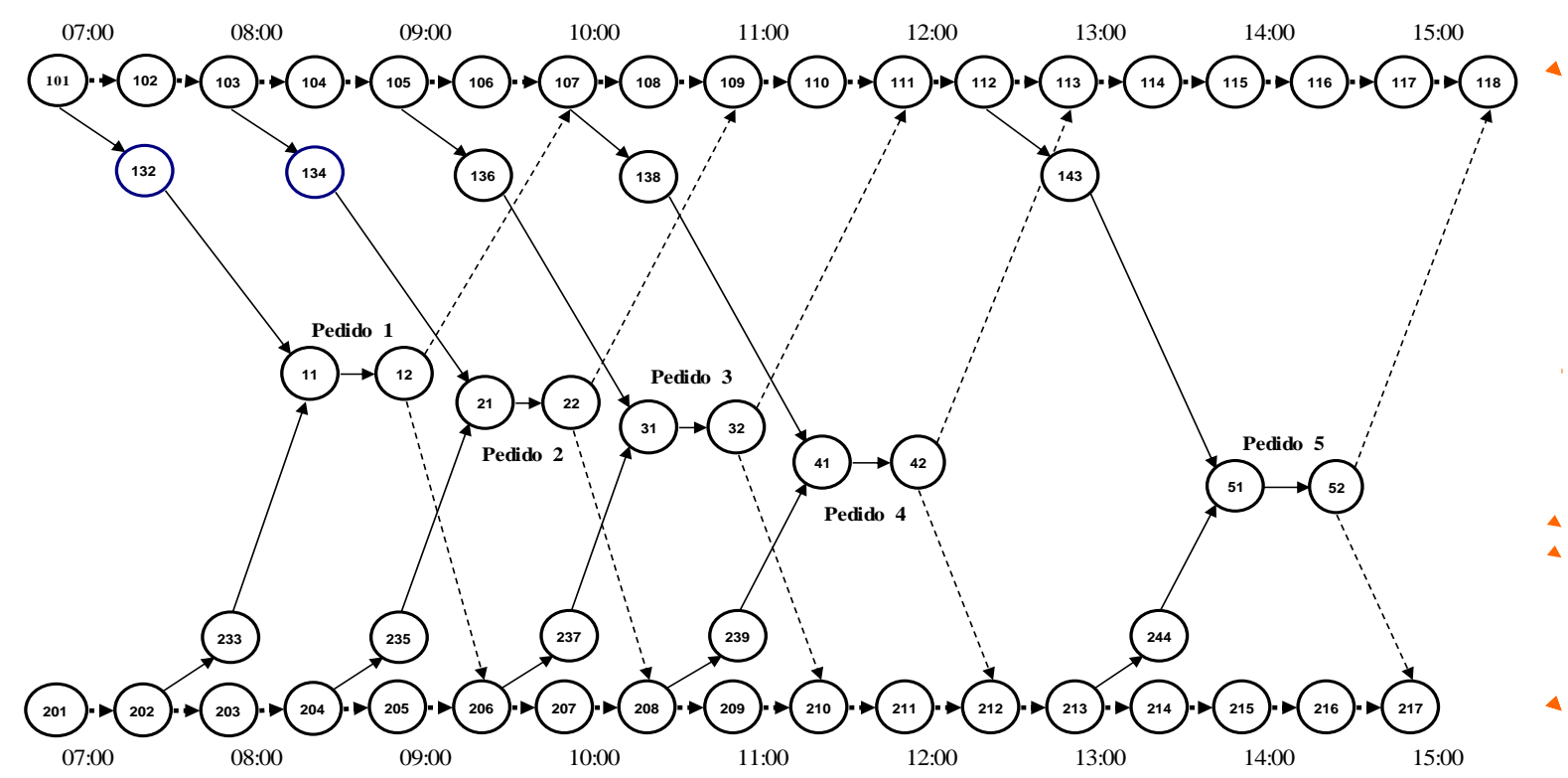

Figura 2 - Tipos de arcos da Rede espaço-tempo da Figura 1

A função objetivo (1) visa a maximizar a receita marginal (ou margem de contribuição) total do sistema, dada pela diferença entre a receita bruta e os custos variáveis de fornecimento do produto. A restrições (2) impõem que os limites mínimos e máximos de cada arco sejam respeitados, enquanto que a restrições (3) garantem que todos os pedidos $p \in P$ de um determinado cliente $j \in J$ sejam integralmente atendidos pela mesma central $i \in I$. Adicionalmente, a restrições (4) garantem o equilíbrio entre o fluxo que entra e o que sai em 
cada um dos nós da rede espaço-tempo. Já a restrições (5) asseguram que cada cliente $j \in J$ só possa ser atendido por uma única central $i \in I$. Finalmente, as restrições (6) impõem que as variáveis de decisão $y_{i j}$ sejam números binários.

Tabela 2 - Arcos da rede espaço- tempo correspondentes à Figura 2

\begin{tabular}{|c|c|c|c|c|}
\hline \multirow{2}{*}{$\begin{array}{l}\text { Arco } \\
(k, l)\end{array}$} & \multirow{2}{*}{ Tipo } & \multicolumn{3}{|c|}{ Atributos } \\
\hline & & $\operatorname{Marg}_{k l}$ & $U_{k l}$ & $L_{k l}$ \\
\hline$(101,102)$ & ArcDisp & 0 & $D_{1}$ & 0 \\
\hline$(102,103)$ & ArcDisp & 0 & $D_{1}$ & 0 \\
\hline$(103,104)$ & ArcDisp & 0 & $D_{1}$ & 0 \\
\hline$(104,105)$ & ArcDisp & 0 & $D_{1}$ & 0 \\
\hline$(105,106)$ & ArcDisp & 0 & $D_{1}$ & 0 \\
\hline$(106,107)$ & ArcDisp & 0 & $D_{1}$ & 0 \\
\hline$(107,108)$ & ArcDisp & 0 & $D_{1}$ & 0 \\
\hline$(108,109)$ & ArcDisp & 0 & $D_{1}$ & 0 \\
\hline$(109,110)$ & ArcDisp & 0 & $D_{1}$ & 0 \\
\hline$(110,111)$ & ArcDisp & 0 & $D_{1}$ & 0 \\
\hline$(111,112)$ & ArcDisp & 0 & $D_{1}$ & 0 \\
\hline$(112,113)$ & ArcDisp & 0 & $D_{1}$ & 0 \\
\hline$(113,114)$ & ArcDisp & 0 & $D_{1}$ & 0 \\
\hline$(114,115)$ & ArcDisp & 0 & $D_{1}$ & 0 \\
\hline$(115,116)$ & ArcDisp & 0 & $D_{1}$ & 0 \\
\hline$(116,117)$ & ArcDisp & 0 & $D_{1}$ & 0 \\
\hline$(117,118)$ & ArcDisp & 0 & $D_{1}$ & 0 \\
\hline$(101,132)$ & ArcCarreg & 0 & $C_{1}$ & 0 \\
\hline$(103,134)$ & ArcCarreg & 0 & $C_{1}$ & 0 \\
\hline$(105,136)$ & ArcCarreg & 0 & $C_{1}$ & 0 \\
\hline$(107,138)$ & ArcCarreg & 0 & $C_{1}$ & 0 \\
\hline$(112,143)$ & ArcCarreg & 0 & $C_{1}$ & 0 \\
\hline$(132,11)$ & ArcCliente $_{j}$ & Marg centrall, cliente & $\infty$ & 0 \\
\hline$(134,21)$ & ArcCliente $_{j}$ & Marg $_{\text {centrall,cliente }}$ & $\infty$ & 0 \\
\hline$(136,31)$ & ArcCliente $_{j}$ & Marg centrall,cliente & $\infty$ & 0 \\
\hline$(138,41)$ & ArcCliente $_{j}$ & Marg centrall,cliente & $\infty$ & 0 \\
\hline$(143,51)$ & ArcCliente $_{j}$ & Marg ${ }_{\text {centrall,cliente }}$ & $\infty$ & 0 \\
\hline$(11,12)$ & ArcAtend & 0 & $b_{j}^{p}$ & $\overline{b_{j}^{p}}$ \\
\hline$(21,22)$ & ArcAtend & 0 & $b_{j}^{p}$ & $b_{j}^{p}$ \\
\hline$(31,32)$ & ArcAtend & 0 & $\frac{j}{b_{j}^{p}}$ & $\frac{1}{b_{j}^{p}}$ \\
\hline$(41,42)$ & ArcAtend & 0 & $b_{j}^{p}$ & $b_{j}^{p}$ \\
\hline$(51,52)$ & ArcAtend & 0 & $b_{i}^{p}$ & $b_{i}^{p}$ \\
\hline
\end{tabular}

\begin{tabular}{|c|c|c|c|c|}
\hline \multirow{2}{*}{$\begin{array}{l}\text { Arco } \\
(k, l)\end{array}$} & \multirow{2}{*}{ Tipo } & \multicolumn{3}{|c|}{ Atributos } \\
\hline & & $\operatorname{Marg}_{k l}$ & $U_{k l}$ & $L_{k l}$ \\
\hline$(12,107)$ & ArcViag $_{\text {volta }}$ & 0 & $\infty$ & 0 \\
\hline$(22,109)$ & ArcViag $_{\text {volta }}$ & 0 & $\infty$ & 0 \\
\hline$(32,111)$ & ArcViag ${ }_{\text {volta }}$ & 0 & $\infty$ & 0 \\
\hline$(42,113)$ & ArcViag volta & 0 & $\infty$ & 0 \\
\hline$(52,118)$ & ArcViag $_{\text {volta }}$ & 0 & $\infty$ & 0 \\
\hline$(201,202)$ & ArcDisp & 0 & $D_{2}$ & 0 \\
\hline$(202,203)$ & ArcDisp & 0 & $D_{2}$ & 0 \\
\hline$(203,204)$ & ArcDisp & 0 & $D_{2}$ & 0 \\
\hline$(204,205)$ & ArcDisp & 0 & $\mathrm{D}_{2}$ & 0 \\
\hline$(205,206)$ & ArcDisp & 0 & $D_{2}$ & 0 \\
\hline$(206,207)$ & ArcDisp & 0 & $D_{2}$ & 0 \\
\hline$(207,208)$ & ArcDisp & 0 & $D_{2}$ & 0 \\
\hline$(208,209)$ & ArcDisp & 0 & $D_{2}$ & 0 \\
\hline$(209,210)$ & ArcDisp & 0 & $D_{2}$ & 0 \\
\hline$(210,211)$ & ArcDisp & 0 & $D_{2}$ & 0 \\
\hline$(211,212)$ & ArcDisp & 0 & $D_{2}$ & 0 \\
\hline$(212,213)$ & ArcDisp & 0 & $D_{2}$ & 0 \\
\hline$(213,214)$ & ArcDisp & 0 & $D_{2}$ & 0 \\
\hline$(214,215)$ & ArcDisp & 0 & $D_{2}$ & 0 \\
\hline$(215,216)$ & ArcDisp & 0 & $D_{2}$ & 0 \\
\hline$(216,217)$ & ArcDisp & 0 & $D_{2}$ & 0 \\
\hline$(202,233)$ & ArcCarreg & 0 & $C_{2}$ & 0 \\
\hline$(204,235)$ & ArcCarreg & 0 & $C_{2}$ & 0 \\
\hline$(206,237)$ & ArcCarreg & 0 & $C_{2}$ & 0 \\
\hline$(208,239)$ & ArcCarreg & 0 & $C_{2}$ & 0 \\
\hline$(213,244)$ & ArcCarreg & 0 & $C_{2}$ & 0 \\
\hline$(233,11)$ & ArcCliente $_{j}$ & Marg $_{\text {central, }, \text { cliente }}$ & $\infty$ & 0 \\
\hline$(235,21)$ & ArcCliente $_{j}$ & Marg $_{\text {central }, \text { cliente }}$ & $\infty$ & 0 \\
\hline$(237,31)$ & ArcCliente $_{j}$ & Marg $_{\text {central2,cliente }}$ & $\infty$ & 0 \\
\hline$(239,41)$ & ArcCliente $_{j}$ & Marg $_{\text {central2,cliente }}$ & $\infty$ & 0 \\
\hline$(244,51)$ & ArcCliente $_{j}$ & Marg $_{\text {central, }, \text { cliente }}$ & $\infty$ & 0 \\
\hline$(12,206)$ & ArcViag $_{\text {volta }}$ & 0 & $\infty$ & 0 \\
\hline$(22,208)$ & ArcViag $_{\text {volta }}$ & 0 & $\infty$ & 0 \\
\hline$(32,210)$ & ArcViag $_{\text {volta }}$ & 0 & $\infty$ & 0 \\
\hline$(42,212)$ & ArcViag volta & 0 & $\infty$ & 0 \\
\hline$(52,217)$ & ArcViag ${ }_{\text {volta }}$ & 0 & $\infty$ & 0 \\
\hline
\end{tabular}




\subsection{Modelo matemático para os casos em que a demanda é maior que a capacidade de atendimento}

O modelo matemático apresentado na seção anterior refere-se às situações onde todos os pedidos devem ser atendidos. Todavia, na prática podem ocorrer situações em que nem todos os pedidos podem ser aceitos, devido a restrições de capacidade. Assim, considera-se que, se houver uma impossibilidade de atendimento de um ou mais pedidos, o modelo definirá quais dos pedidos deverão ser atendidos, objetivando a maximização do retorno como um todo.

Dessa forma, o modelo matemático é similar ao apresentado anteriormente (1-6), com pequenas diferenças conforme detalhado a seguir:

$\operatorname{maximizar} \sum_{(k, l) \in A} \operatorname{Marg}_{k l} x_{k l}$

Sujeito a:

$$
\begin{array}{ll}
L_{k l} \leq x_{k l} \leq U_{k l} & \forall(k, l) \in A \\
x_{k l} \leq y_{i j} U_{k l} & \forall(k, l) \in \text { ArcCliente }_{j}, \forall i \in I \text { e } \forall j \in J \\
\sum_{(l, k) \in A} x_{l k}-\sum_{(k, l) \in A} x_{k l}=0 & \forall k \in N \\
\sum_{i} y_{i j}=1 & \forall j \in J \\
& \\
y_{i j} \in\{0,1\} &
\end{array}
$$

Para finalizar, pode-se ainda considerar que apenas um determinado cliente $j \in J$ ou ainda que apenas um determinado pedido de um cliente específico $p \in P_{j}$ devesse ser obrigatoriamente atendido. Um recurso disponível para isso, seria considerar que para esse(s) arco(s) específico(s) $(k, l) \in$ ArcAtend, $\quad L_{k l}=U_{k l}=b_{j}^{p}$, de maneira a obrigar que o fluxo nesse(s) $\operatorname{arco}(\mathrm{s})(k, l)$ específico(s) corresponda(m) ao atendimento integral do pedido. 


\section{Sistema de Apoio à Decisão (SAD) baseado em planilha Excel}

Optou-se por implementar o modelo proposto na Seção 3 em ambiente de planilha eletrônica no Microsoft Excel tendo em vista a sua disseminação no ambiente empresarial, assim como a facilidade de desenvolvimento, permitindo construir uma ferramenta amigável, que pode ser utilizada rotineiramente como auxílio à programação de entrega do concreto.

Conforme apontam Seref et al. (2007), modelos de apoio à decisão, em particular os baseados em técnicas de Pesquisa Operacional, requerem interfaces gráficas e amigáveis que não só permitam como também facilitem a interação com os usuários, inclusive aqueles não familiarizados com essas sofisticadas técnicas matemáticas e seus detalhes. Dessa forma, o SAD foi desenvolvido visando facilitar a utilização do modelo por usuários leigos. A partir de dados fornecidos pelo usuário e, através de automatização de funções e rotinas, a rede e cada um dos componentes do modelo matemático (função objetivo e restrições) são construídos, o modelo é resolvido e os resultados são apresentados sem necessidade de intervenção do usuário.

O modelo matemático é solucionado através pacote de otimização que tem condições de interpretá-lo e executá-lo, mais especificamente o Premium Solver Platform versão 9.0.4.0 (que corresponde a uma versão profissional paga, com maior capacidade em termos de número de variáveis de decisão e mais eficiente que a que acompanha o Solver); a linguagem de programação VBA ("Visual Basic for Applications") foi utilizada como apoio à ferramenta.

Tendo em vista a natureza do problema, onde muitos dos pedidos são modificados durante o dia e novos pedidos aparecem continuamente, a ferramenta foi estruturada de forma a possibilitar a sua utilização para reprogramações periódicas, mantendo os pedidos já programados, e reprogramando as alterações (e os novos pedidos).

O esquema de funcionamento da ferramenta é sumarizado na Figura 3. Inicialmente devem ser inseridos os dados de entrada que vão ser utilizados pelo modelo. Esse é o único momento em que o usuário interfere no funcionamento da ferramenta. 


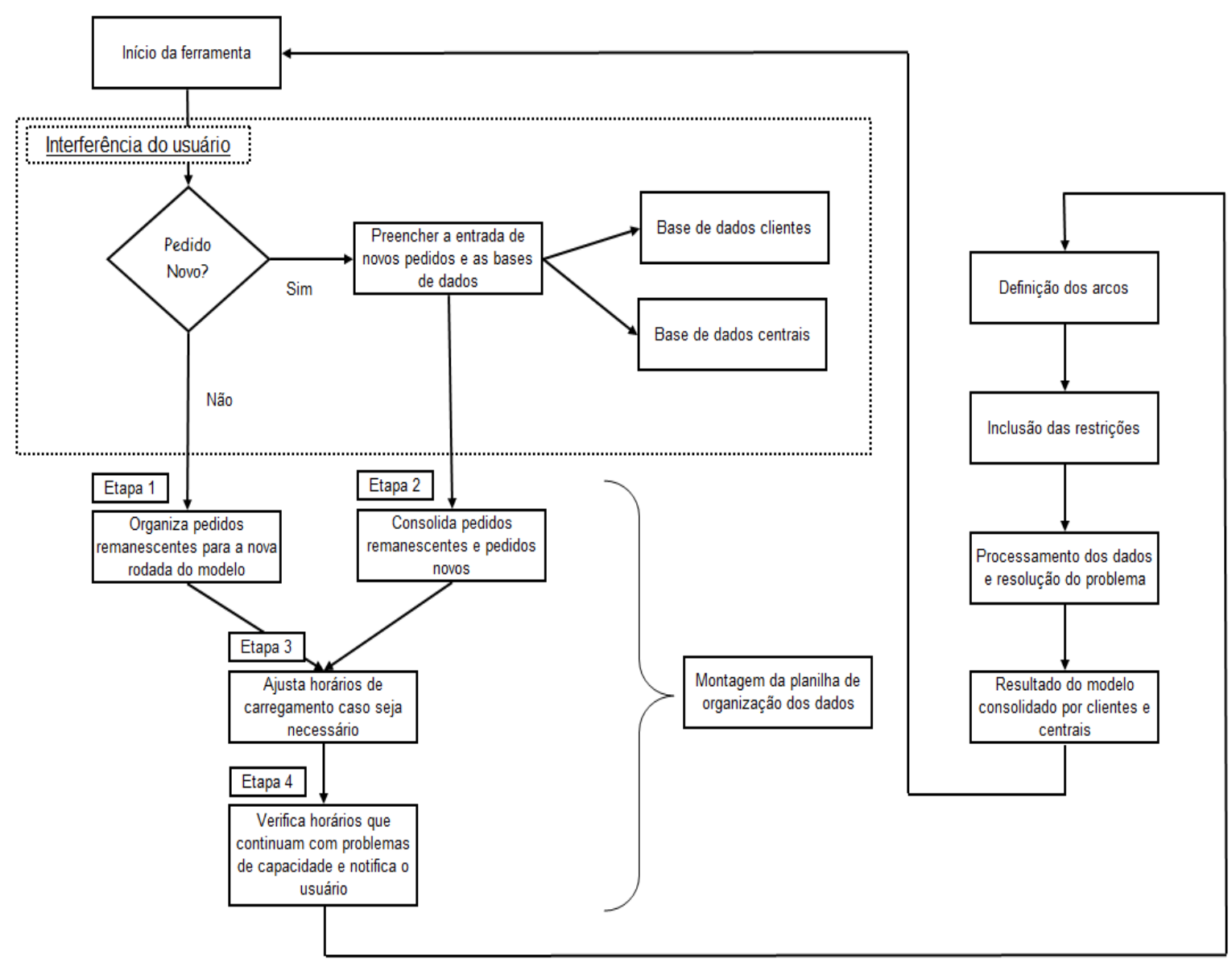

Figura 3 - Esquema de funcionamento da ferramenta para programação de carregamento e entrega de concreto

Existem dois conjuntos principais de dados a serem preenchidos: dados dos pedidos a serem programado, dados dos clientes e das centrais considerados na programação. Os dados dos pedidos precisam definir o nome do cliente $j \in J$, a quantidade desejada de concreto $\left(b_{j}^{p}\right)$ e o horário solicitado para a entrega $\left(h_{j}^{p}\right)$ do material.

Conforme ilustrado na Figura 4, além da inserção de novos pedidos, o usuário deve também inserir, os parâmetros que serão utilizados pelo modelo durante a execução da ferramenta, que são: o intervalo estimado entre carregamentos em cada central, a capacidade do caminhão (em toneladas) e o overbooking máximo (expresso como uma porcentagem da capacidade) previsto para a operação. 


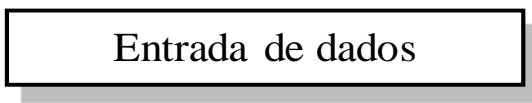

\section{Centrais dosadoras de concreto}

\section{Quantidade de centrais}

Intervalo entre carregamentos

Capacidade do caminhão (em toneladas)

Overbooking

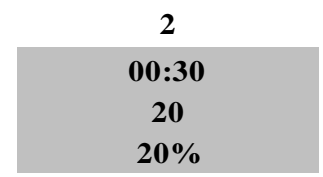

$20 \%$

Quantidade de clientes - novos pedidos

Número de pedidos novos

Entrada de pedidos

\begin{tabular}{|c|c|c|}
\hline Cliente & $\begin{array}{c}\text { Horário de } \\
\text { recebimento }\end{array}$ & $\begin{array}{c}\text { Necessidade de } \\
\text { concreto } \\
\text { (em toneladas) }\end{array}$ \\
\hline \hline Cliente B & $08: 30$ & 20 \\
Cliente A & $08: 00$ & 40 \\
Cliente A & $09: 30$ & 20 \\
Cliente D & $13: 30$ & 40 \\
Cliente A & $14: 00$ & 60 \\
Cliente G & $12: 30$ & 40 \\
Cliente G & $15: 30$ & 20 \\
Cliente B & $09: 30$ & 60 \\
Cliente A & $14: 30$ & 20 \\
Cliente C & $11: 00$ & 20 \\
Cliente B & $16: 00$ & 60 \\
Cliente D & $12: 30$ & 40 \\
Cliente B & $09: 30$ & 60 \\
Cliente C & $16: 30$ & 20 \\
Cliente C & $12: 00$ & 20 \\
Cliente F & $11: 10$ & 40 \\
Cliente F & $13: 00$ & 40 \\
Cliente B & $09: 30$ & 60 \\
Cliente B & $15: 00$ & 20 \\
Cliente C & $08: 00$ & 60 \\
\hline
\end{tabular}

Figura 4 - Planilha de entrada de novos pedidos e dos parâmetros do problema

O segundo conjunto de dados a serem preenchidos pelo usuário corresponde aos dados referentes às centrais dosadoras de concreto disponíveis para atendimento dos pedidos, e aos dados dos clientes que fazem parte da programação (Figura 5). Mais especificamente, para as centrais devese informar a capacidade de carregamento por período $\left(C_{i}\right)$ e a disponibilidade inicial de caminhões próprios $\left(D_{i}\right)$. Esses dados são os parâmetros das restrições de capacidade e disponibilidade de caminhões, respectivamente. Já em relação aos dados dos clientes, os tempos de viagem (ou deslocamento) $\left(t_{i j}\right)$ do percurso entre cada central $i \in I$ e cada cliente $j \in J$, tempos 
de descarregamento no cliente $\left(t d_{j}^{p}\right)$ e as margens de contribuição $\left(\operatorname{Marg}_{k l}\right)$ por caminhão esperadas para o atendimento feito por cada central devem ser aqui informados.

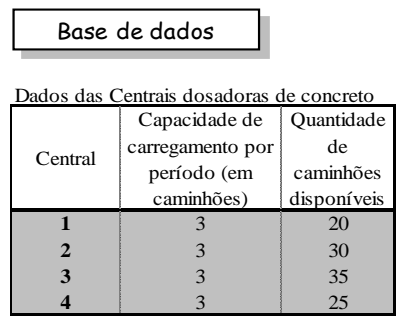

Dados dos clientes
\begin{tabular}{|c|c|c|c|c|c|c|c|c|c|}
\hline Cliente & $\begin{array}{c}\text { Tempo de } \\
\text { viagem } \\
\text { Central 1 }\end{array}$ & $\begin{array}{c}\text { Margem de } \\
\text { contribuição } \\
\text { Central 1 }\end{array}$ & $\begin{array}{c}\text { Tempo de } \\
\text { viagem } \\
\text { Central 2 }\end{array}$ & $\begin{array}{c}\text { Margem de } \\
\text { contribuição } \\
\text { Central 2 }\end{array}$ & $\begin{array}{c}\text { Tempo de } \\
\text { viagem } \\
\text { Central 3 }\end{array}$ & $\begin{array}{c}\text { Margem de } \\
\text { contribuição } \\
\text { Central 3 }\end{array}$ & $\begin{array}{c}\text { Tempo de } \\
\text { viagem } \\
\text { Central 4 }\end{array}$ & $\begin{array}{c}\text { Margem de } \\
\text { contribuição } \\
\text { Central 4 }\end{array}$ & $\begin{array}{c}\text { Tempo de } \\
\text { descarregamento } \\
\text { no cliente }\end{array}$ \\
\hline Cliente A & $00: 19: 00$ & $\$ 13$ & $00: 25: 00$ & $\$ 12$ & $00: 31: 00$ & $\$ 11$ & $00: 45: 00$ & $\$ 10$ & $00: 35: 00$ \\
Cliente B & $01: 15: 00$ & $\$ 9$ & $00: 45: 00$ & $\$ 11$ & $01: 20: 00$ & $\$ 8$ & $01: 25: 00$ & $\$ 7$ & $00: 30: 00$ \\
Cliente C & $00: 29: 00$ & $\$ 9$ & $01: 05: 00$ & $\$ 8$ & $00: 25: 00$ & $\$ 10$ & $00: 37: 00$ & $\$ 9$ & $00: 25: 00$ \\
Cliente D & $00: 55: 00$ & $\$ 5$ & $00: 32: 00$ & $\$ 9$ & $00: 24: 00$ & $\$ 11$ & $00: 10: 00$ & $\$ 12$ & $00: 30: 00$ \\
Cliente E & $00: 15: 00$ & $\$ 16$ & $00: 25: 00$ & $\$ 14$ & $00: 33: 00$ & $\$ 12$ & $00: 52: 00$ & $\$ 9$ & $00: 40: 00$ \\
Cliente F & $00: 36: 00$ & $\$ 14$ & $00: 21: 00$ & $\$ 15$ & $00: 43: 00$ & $\$ 10$ & $00: 57: 00$ & $\$ 8$ & $00: 25: 00$ \\
Cliente G & $00: 30: 00$ & $\$ 11$ & $00: 15: 00$ & $\$ 9$ & $00: 32: 00$ & $\$ 11$ & $00: 19: 00$ & $\$ 9$ & $00: 25: 00$ \\
\hline
\end{tabular}

\section{Figura 5 - Base de dados dos clientes e das centrais dosadoras de concreto}

Depois da inserção de todos estes dados de entrada, o usuário deve clicar um botão que aciona as macros construídas em linguagem VBA com a finalidade de construir a rede, criar o modelo matemático (englobando variáveis de decisão, função objetivo e restrições), e chamar o Solver para a obtenção da solução ótima para o problema de programação considerado. Tudo isso é feito de maneira automática, até o resultado final, onde serão definidos os horários de carregamento e as centrais que deverão atender cada um dos pedidos.

O processo automático de obtenção da solução ótima inicia-se com a montagem da planilha “organização dos dados" (ilustrada na Figura 3), a qual tem por finalidade organizar todos os dados para a execução do software de otimização Solver, para obter a solução ótima. Essa planilha tem a seguinte estrutura: cada uma das linhas considera um pedido $p \in P_{j}$, enquanto que, nas colunas têm-se os nomes dos clientes $j \in J$, as margens de contribuição (Marg $k$ l) para cada opção de carregamento (em cada uma das centrais), o horário solicitado para a entrega $h_{j}^{p}$ de cada um dos pedidos, o horário de carregamento em cada uma das centrais, assim como o horário de retorno dos caminhões caso seja atendido por cada central.

Após a montagem da planilha "organização dos dados", a rotina VBA constrói todos os nós e $\operatorname{arcos}$ da rede em questão e a macro responsável por esta função, os organiza em forma de planilha conforme ilustrado na Figura 6. É especificado o conjunto ArcViag $g_{i d a} \subset A$ dos arcos de viagem de ida $(k, l) \in A$ que ligam as centrais aos clientes e que representam, dessa forma, a possibilidade de atendimento de um pedido de um cliente $i \in I$ por uma central $j \in J$. É definida a célula que corresponde à função objetivo e na seqüência, a ferramenta considera todas as 
restrições do modelo: (i) de atendimento de todos os pedidos; (ii) de que todos os pedidos de um determinado cliente sejam atendidos pela mesma central; (iii) as que impõem que as capacidades de abastecimento de cada central e o overbooking máximo estipulado não sejam ultrapassados; (iv) e a responsável pelo controle da disponibilidade de caminhões por período de tempo. Finalmente, através da rotina VBA, a ferramenta define todas as células variáveis do modelo $\left(x_{k l}\right.$ e $y_{i j}$ ). Com isso, é possível executar o software de otimização Solver, o qual determinará a solução de maior valor de margem de contribuição para a rede apresentada. Isto é, serão definidos os arcos que serão utilizados para a entrega de cada pedido de cada cliente.

Uma vez que a solução do modelo tenha sido determinada, a ferramenta montará a tabela de apresentação dos resultados "Base de pedidos programados" conforme a Figura 7, e assim o processo será finalizado.

Conforme mostrado na Figura 7, o SAD exibe os resultados de maneira detalhada, englobando:

- o nome do cliente $j \in J$, o horário solicitado para o recebimento $h_{j}^{p}$, a quantidade de concreto a ser entregue $b_{j}^{p}$ e o número de viagens necessárias (dados fornecidos pelo usuário);

- a central $i \in I$, programada para atendê-lo (resultado do modelo);

- a margem de contribuição calculada para o atendimento do pedido conforme as condições que foi programado (resultado do modelo);

- o horário planejado para o carregamento do caminhão na central específica (resultado do modelo);

- o horário previsto para o retorno do caminhão à central (resultado do modelo);

- o status do pedido, confirmado ou cancelado (resultado do modelo);

- $\quad$ se o horário de carregamento foi ou não ajustado (antecipado);

- para os casos em que o horário foi ajustado, a quantidade de minutos que o carregamento foi antecipado. (resultado do modelo). 
Além disso, a ferramenta também calcula os dados totais de margens de contribuição, e quantidades em toneladas de concreto, por clientes e por centrais.

\section{Testes para Verificação do Funcionamento do Modelo e da Ferramenta}

Inicialmente, foram realizados testes com instâncias de dimensões reduzidas do problema de programação de carregamento e entrega de concreto, em termos de número de centrais e de clientes, buscando verificar tanto o funcionamento do SAD quanto a correção do modelo de otimização. Por se tratarem de problemas singelos e de fácil solução manual, a solução ótima foi obtida tanto manualmente como computacionalmente (através do software de otimização do SAD), o que permitiu a comparação dos resultados e confirmou o correto funcionamento do modelo, em termos das restrições e função objetivo, e também da sua implementação em ambiente de planilha eletrônica.

Mais especificamente, os testes de funcionamento englobaram as seguintes verificações: geração de cada um dos tipos de arco do modelo,

Também foram realizados testes considerando instâncias de porte um pouco maior, ou seja, instâncias mais realistas de tal forma que pudesse se verificar se as restrições e todas as particularidades do modelo continuavam se comportando corretamente para problemas de proporções reais. Vários foram os testes realizados com esse propósito. Variaram-se o número de centrais, de pedidos, de clientes e de tamanho de cada pedido. Foram feitos testes considerandose 2, 3 e 4 centrais dosadoras de concreto e números de pedidos iguais a 10,20, 30 e 40 , com 3, 6, 8 e 10 clientes. Além disso, variou-se o tamanho dos pedidos a fim de considerar pequenas, médias e grandes quantidades de concreto no pedido. Maiores detalhes sobre os resultados obtidos podem ser encontrados em Cortes (2011). 


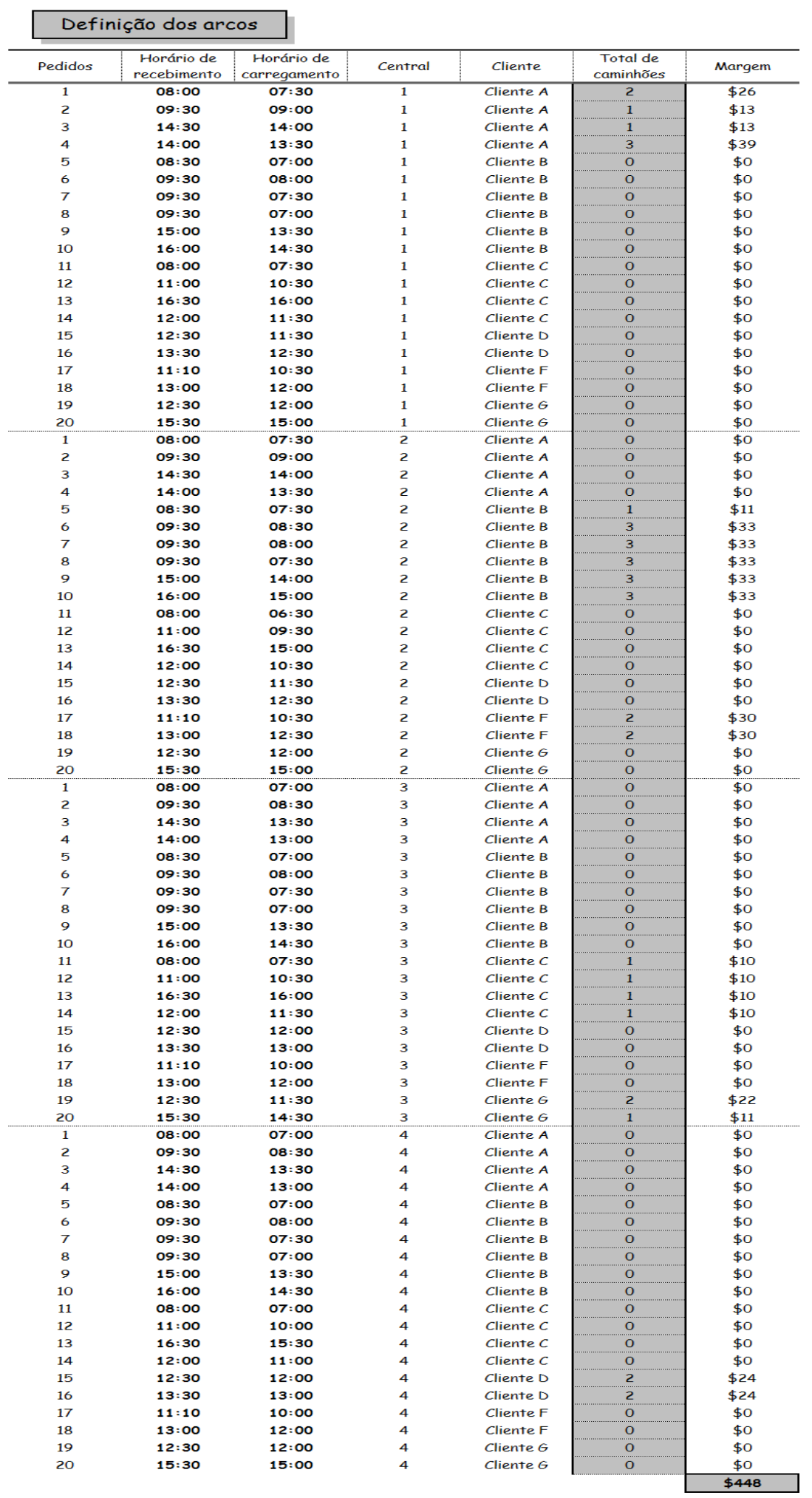

Figura 6 - Exemplo de uma planilha da rede 


\begin{tabular}{|c|c|c|c|c|c|c|c|c|c|c|c|c|c|c|c|c|c|}
\hline \multicolumn{4}{|c|}{ Início do modelo } & & & & & & & & & & & & & & \\
\hline \multirow{2}{*}{\multicolumn{18}{|c|}{$\begin{array}{l}\text { Dados } \\
\text { Quantidade de centrais }\end{array}$}} \\
\hline \multirow{2}{*}{\multicolumn{3}{|c|}{$\begin{array}{l}\text { Quantiddde de centrais } \\
\text { Quantidade de clientes }\end{array}$}} & 4 & & & & & & & & & & & & & & \\
\hline & & & 6 & & & & & & & & & & & & & & \\
\hline \multicolumn{3}{|c|}{ Quantidade de pedidos } & 20 & & & & & & & & & & & & & & \\
\hline \multirow{2}{*}{\multicolumn{3}{|c|}{$\begin{array}{l}\text { Intervali - carregagmimentros } \\
\text { Capacidode do caminhão }\end{array}$}} & $00: 30$ & & & & & & & & & & & & & & \\
\hline & & & 20 & & & & & & & & & & & & & & \\
\hline & & & & & & Pedidos & Cliente & $\begin{array}{l}\text { Horário de } \\
\text { recebimento }\end{array}$ & \begin{tabular}{|c|} 
Necessidade \\
de concreto \\
$($ em \\
toneladas $)$
\end{tabular} & $\begin{array}{l}\text { Total do } \\
\text { pedido em } \\
\text { caminhões }\end{array}$ & \begin{tabular}{|c|} 
Central \\
que \\
atenderá 0 \\
pedido
\end{tabular} & $\begin{array}{c}\text { Margem de } \\
\text { contribuição } \\
\text { esperada }\end{array}$ & $\begin{array}{c}\text { Horário de } \\
\text { carregamento } \\
\text { na Central }\end{array}$ & $\begin{array}{l}\text { Horário } \\
\text { previsto de } \\
\text { retorno à } \\
\text { Central }\end{array}$ & $\begin{array}{c}\text { Status do } \\
\text { pedido }\end{array}$ & $\begin{array}{l}\text { Horário foi } \\
\text { ajustado? }\end{array}$ & $\begin{array}{l}\text { Quanto } \\
\text { tempo? }\end{array}$ \\
\hline \multicolumn{6}{|c|}{ Total de concreto programado (toneladas) } & 1 & Cliente A & 08:00 & 40 & 2 & 1 & $\$ 26$ & $07: 30$ & 09:00 & $\overline{\text { Confirmado }}$ & Não & - \\
\hline Cliente & Central 1 & Central 2 & Central 3 & Central 4 & Total & 2 & Cliente A & 09:30 & 20 & 1 & 1 & $\$ 13$ & 09:00 & 10:30 & Confirmado & Não & - \\
\hline Cliente $A$ & 140 & 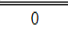 & 0 & 0 & 140 & 3 & Cliente A & 14:30 & 20 & 1 & 1 & $\$ 13$ & 14:00 & $15: 30$ & Confirmado & Não & - \\
\hline Cliente B & 0 & 320 & 0 & 0 & 320 & 4 & Cliente A & 14:00 & 60 & 3 & 1 & $\$ 39$ & $13: 30$ & $15: 00$ & Confirmado & Não & - \\
\hline Clientec & 0 & 0 & 80 & 0 & 80 & 5 & Cliente B & 08:30 & 20 & 1 & 2 & $\$ 11$ & 07:30 & 10:00 & Confirmado & Não & - \\
\hline Cliente D & 0 & 0 & 0 & 80 & 80 & 6 & Cliente B & 09:30 & 60 & 3 & 2 & $\$ 33$ & $08: 30$ & 11:00 & Confirmado & Não & - \\
\hline Cliente F & 0 & 80 & 0 & 0 & 80 & 7 & Cliente B & 09:30 & 60 & 3 & 2 & $\$ 33$ & 08:00 & 11:00 & Confirmado & Sim & $00: 30$ \\
\hline \multirow[t]{3}{*}{ Cliente G } & 0 & 0 & 60 & 0 & 60 & 8 & Cliente B & 09:30 & 60 & 3 & 2 & $\$ 33$ & 07:30 & 11:00 & Confirmado & Sim & 01:00 \\
\hline & 140 & 400 & 140 & 80 & 760 & 9 & Cliente B & 15:00 & 60 & 3 & 2 & $\$ 33$ & 14:00 & $16: 30$ & Confirmado & Não & - \\
\hline & & & & & & 10 & Cliente B & 16:00 & 60 & 3 & 2 & $\$ 33$ & 15:00 & $17: 30$ & Confirmado & Não & - \\
\hline \multicolumn{6}{|c|}{ Margem de contribuição projetada } & 11 & Cliente C & 08:00 & 20 & 1 & 3 & $\$ 10$ & 07:30 & 09:00 & Confirmado & Não & - \\
\hline Cliente: & Central 1 & Central 2 & Central 3 & Central 4 & Total & 12 & Cliente C & 11:00 & 20 & 1 & 3 & $\$ 10$ & 10:30 & 12:00 & Confirmado & Não & - \\
\hline Cliente A & $\$ 91$ & $\$ 0$ & $\$ 0$ & $\$ 0$ & $\$ 91$ & 13 & Cliente C & $16: 30$ & 20 & 1 & 3 & $\$ 10$ & 16:00 & 17:30 & Confirmado & Não & - \\
\hline Cliente B & $\$ 0$ & $\$ 176$ & $\$ 0$ & $\$ 0$ & $\$ 176$ & 14 & Cliente C & 12:00 & 20 & 1 & 3 & $\$ 10$ & $11: 30$ & 13:00 & Confirmado & Não & - \\
\hline Cliente C & $\$ 0$ & $\$ 0$ & $\$ 40$ & $\$ 0$ & $\$ 40$ & 15 & Cliente D & $12: 30$ & 40 & 2 & 4 & $\$ 24$ & 12:00 & $13: 30$ & Confirmado & Não & - \\
\hline Cliente D & $\$ 0$ & $\$ 0$ & $\$ 0$ & $\$ 48$ & $\$ 48$ & 16 & Cliente D & $13: 30$ & 40 & 2 & 4 & $\$ 24$ & 13:00 & $14: 30$ & Confirmado & Não & - \\
\hline Cliente F & $\$ 0$ & $\$ 60$ & $\$ 0$ & $\$ 0$ & $\$ 60$ & 17 & Cliente F & 11:10 & 40 & 2 & 2 & $\$ 30$ & 10:30 & 12:00 & Confirmado & Não & - \\
\hline \multirow[t]{3}{*}{ Cliente 6} & $\$ 0$ & $\$ 0$ & $\$ 33$ & $\$ 0$ & $\$ 33$ & 18 & Cliente F & 13:00 & 40 & 2 & 2 & $\$ 30$ & 12:30 & 14:00 & Confirmado & Não & - \\
\hline & $\$ 91$ & $\$ 236$ & $\$ 73$ & $\$ 48$ & $\$ 448$ & 19 & Cliente $G$ & $12: 30$ & 40 & 2 & 3 & $\$ 22$ & 11:30 & 13:30 & Confirmado & Não & - \\
\hline & & & & & & 20 & Cliente $G$ & $15: 30$ & 20 & 1 & 3 & $\$ 11$ & 14:30 & $16: 30$ & Confirmado & Não & - \\
\hline
\end{tabular}

\section{Figura 7 - Base de pedidos programados}

Os testes possibilitaram verificar o correto funcionamento da ferramenta, em particular das rotinas de leitura dos dados e de montagem do modelo matemático correspondente, em termos da função objetivo e das restrições, incluindo o caso em que havia a possibilidade de não atendimento de um ou mais pedidos.

Outro teste realizado abordou uma situação onde não era possível se obter uma solução viável, por falta de capacidade do sistema como um todo. Conforme era esperado, o modelo notificou ao usuário que não seria possível atender à demanda proposta, indicando quais eram os pedidos que estavam acarretando esta inviabilidade da solução seja por falta de capacidade de carregamento, falta de caminhões, por overbooking ou ainda, e principalmente, pela restrição que garante que o atendimento de todos os pedidos de um mesmo cliente seja realizado por uma única central. 


\section{Aplicação do Modelo a um Problema Real}

Uma vez verificado o correto funcionamento do SAD (em termos da montagem do modelo matemático e da obtenção de soluções ótimas, respeitando todas as restrições do problema), partiu-se para a aplicação do mesmo a um problema real de programação de entregas de concreto. Para isso, foram obtidos dados de uma empresa do setor que já havia participado dos levantamentos para entendimento do problema no contexto brasileiro. Trata-se de uma empresa de porte nacional, com 120 centrais e 800 caminhões betoneiras em dez estados brasileiros.

Mais especificamente, foram levantados dados relativos à Região Metropolitana de São Paulo, que representa cerca de um terço do total de concreto comercializado pela empresa, e onde a sua participação de mercado está em torno de 25\%. São cerca de 220 caminhões betoneiras circulando diariamente nessa região, realizando em média de 14.500 entregas por mês, em aproximadamente 1.100 clientes, a partir de 11 centrais dosadoras de concreto que funcionam em dias úteis, no horário comercial, produzindo uma média de 110 mil metros cúbicos de concreto por mês.

A Figura 8 mostra uma tela do sistema de cadastro de pedidos de entregas da empresa com a localização das 11 centrais dosadoras de concreto localizadas na Grande São Paulo e suas respectivas áreas de influência, tendo em vista a duração máxima de viagem de acordo com tempo de endurecimento do concreto e as condições de trânsito.

Uma pesquisa realizada pela empresa com os seus clientes em 2004 sobre o que eles consideravam importante na hora de escolher um fornecedor de concreto foram indicou como fatores mais importantes: a qualidade do concreto , com $20 \%$ das respostas, o cumprimento dos horários de entrega , com 15,7\% e a capacidade de receber aceitar pedidos e confirmar horários com $11,3 \%$.

Isso levou a empresa a desenvolver um software de programação de entregas, envolvendo programação, rastreamento, acompanhamento e despacho dos veículos de entregas, para o conjunto de centrais da RMSP. Até então, a empresa não trabalhava com a programação de uma forma centralizada entre as centrais, ou seja, cada uma funcionava de uma forma independente. Quando uma programação era cancelada em uma central, ela ficava ociosa, porque nem sempre havia outro pedido para atender. Enquanto isso, outra central poderia estar precisando de espaço 
disponível para carregamento. Cada uma agia independentemente, e não era possível a otimização da programação.

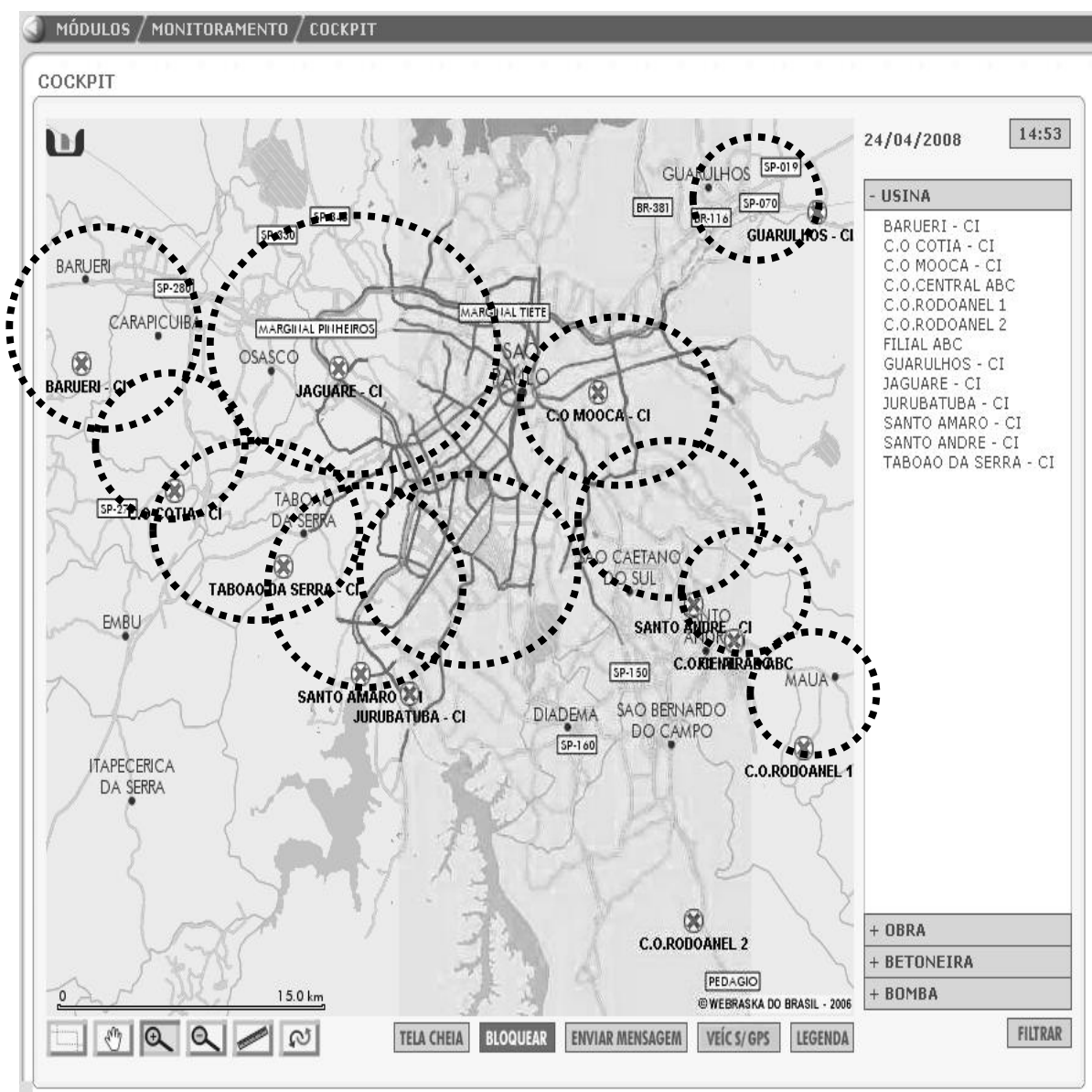

Figura 8 - Tela do sistema utilizado pela empresa com o detalhe da localização das centrais dosadoras na RMSP

Com a instalação desse sistema, a programação diária que era feita em cada unidade passou a ser consolidada por uma central de logística. $\mathrm{O}$ funcionamento da mesma pode ser sumarizado da seguinte forma: o cliente entra em contato informando a sua necessidade e localização. São indicadas as centrais de dosagem mais indicadas para aquela entrega, no melhor tempo e na menor distância em função da velocidade média em cada trecho do trajeto. Com base nisso, os pedidos são direcionados para um subgrupo de centrais da Grande São Paulo que fica responsável então pelo atendimento desta demanda.

A empresa demonstrou interesse na avaliação da ferramenta proposta para os conjuntos de filiais em regiões metropolitanas e cidades menores, que ainda não possuem um sistema de programação e otimização das entregas, uma vez que os custos de implantar, operar e manter um 
sistema corporativo não justificam os benefícios dele advindos. Nesse caso, uma ferramenta mais de concepção mais simples, que resultasse em programação de entregas otimizada, proporcionaria os mesmos benefícios sem o ônus de um sistema corporativo, que exige montar e manter uma base de dados ampla para alimentá-lo, além operadores treinados e capacitados a operá-los.

Foram fornecidos os dados de um dia de típico de produção, conforme mostrado na Figura 9, que indica, para cada um dos 23 pedidos, os quais podem ser atendidos por um conjunto de quatro centrais dosadoras, o volume total da demanda $\left(\mathrm{em}^{3}\right)$ e o horário de início de descarga, ou seja, o horário para a entrega do primeiro caminhão (caso haja uma sequência de entregas). A identificação dos clientes foi alterada de forma a preservar o sigilo da empresa.

$\begin{array}{cccc}\text { Pedido } & \begin{array}{c}\text { Volume Total } \\ \left(\mathbf{m}^{\mathbf{3}} \mathbf{)}\right.\end{array} & \text { Horário Inicio Obra } & \text { Cliente } \\ 61200 & 6,0 & 07: 25 & \text { Cliente 1 } \\ 61201 & 15,0 & 07: 40 & \text { Cliente 1 } \\ 61202 & 55,0 & 08: 00 & \text { Cliente 2 } \\ 61203 & 21,0 & 08: 00 & \text { Cliente 3 } \\ 61204 & 16,0 & 08: 00 & \text { Cliente 4 } \\ 61205 & 6,0 & 08: 15 & \text { Cliente 4 } \\ 61206 & 30,0 & 09: 55 & \text { Cliente 4 } \\ 61207 & 24,0 & 10: 00 & \text { Cliente 4 } \\ 61208 & 4,0 & 10: 00 & \text { Cliente 4 } \\ 61209 & 7,0 & 10: 00 & \text { Cliente 5 } \\ 61210 & 12,0 & 10: 05 & \text { Cliente 5 } \\ 61211 & 10,0 & 11: 00 & \text { Cliente 6 } \\ 61212 & 7,0 & 11: 00 & \text { Cliente 6 } \\ 61213 & 20,0 & 11: 40 & \text { Cliente 6 } \\ 61214 & 30,0 & 12: 00 & \text { Cliente 6 } \\ 61215 & 74,0 & 10: 00 & \text { Cliente 7 } \\ 61216 & 21,0 & 12: 00 & \text { Cliente 8 } \\ 61217 & 4,0 & 13: 00 & \text { Cliente 9 } \\ 61218 & 16,0 & 14: 00 & \text { Cliente 9 } \\ 61219 & 16,0 & 14: 20 & \text { Cliente 10 }\end{array}$

\section{Figura 9 - Dados para a programação de um dia típico de uma central da Grande São Paulo}

Os clientes enviam os pedidos com 20 dias de antecedência para a garantia das quantidades e também para que possam ser realizadas as compras de matéria-prima pela empresa. Com 10 dias de antecedência é solicitada pela empresa uma confirmação dos pedidos e, no dia anterior, a área de logística faz contato com o cliente para a confirmação da entrega. 
Vale ressaltar que, a empresa trabalha com $20 \%$ de overbooking como parâmetro para a sua programação e a capacidade dos caminhões betoneiras aqui tratados são de 20 toneladas de material.

Os dados de entrada dos clientes, conforme alimentados no SAD são mostrados na Figura 10, enquanto que a Figura 11 exibe os dados de margem de contribuição e tempos de viagem para cada uma das quatro centrais dosadoras, assim como os tempos de descarregamento nos clientes.

\section{Entrada de novos pedidos}

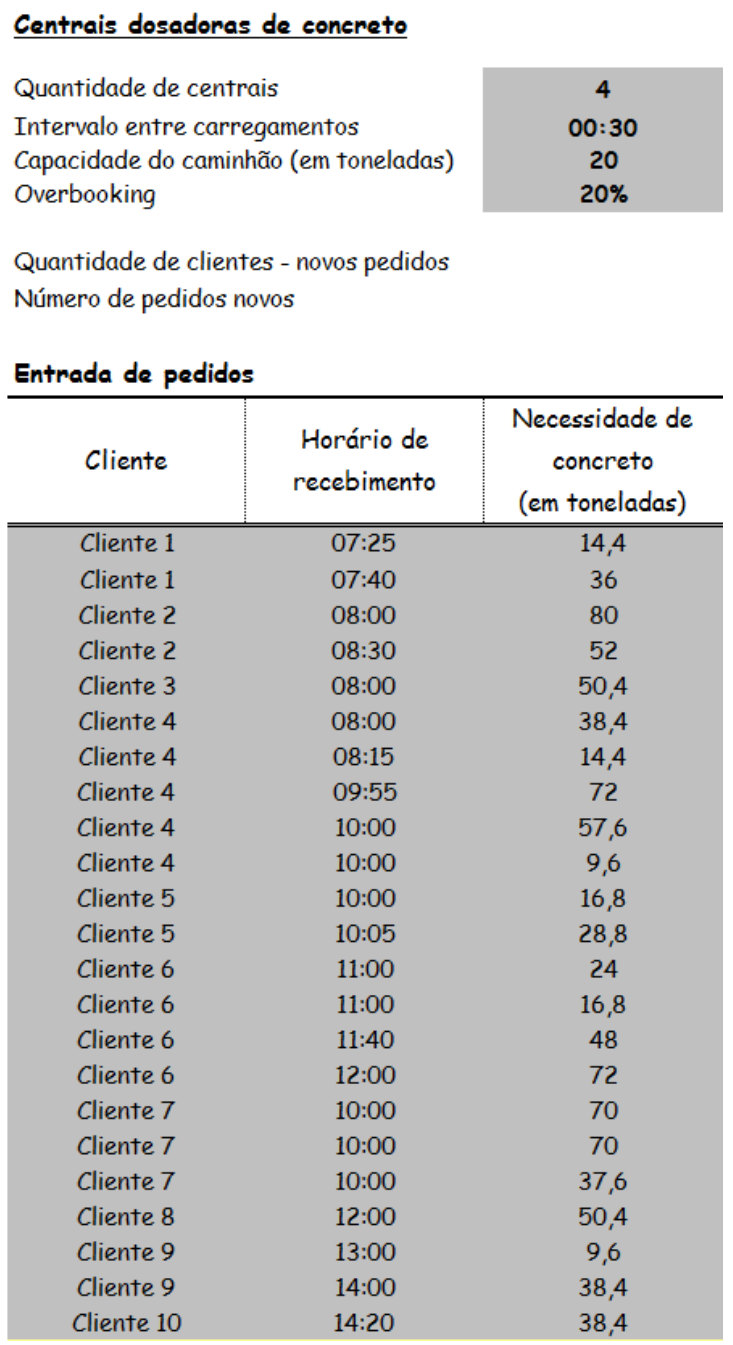

Figura 10 - Entrada de dados - exemplo aplicação do modelo à um caso real

Os testes foram realizados em um PC Pentium $I V, 1,8 \mathrm{GHz}$ e $512 \mathrm{MB}$ de memória RAM e os resultados da programação otimizada estão apresentados na Figura 12. 
O modelo matemático encontrou a solução ótima em 22 segundos, incluindo os tempos de montagem das planilhas necessárias, ajustes de horários e otimização da solução. Verificou-se que todas as restrições do problema (capacidade de carregamento e frota de caminhões disponível por central) foram respeitadas.

Uma análise dos resultados da Figura 12 indicam, para o Cliente 8, por exemplo, que embora a maior margem de contribuição unitária seja o atendimento feito pela Central 2 (R\$ 11 por tonelada), o resultado otimizado indica o atendimento pela Central 1 (com margem de contribuição unitária de $\mathrm{R} \$ 9$ por tonelada). Isso ocorre em decorrência do Pedido 15 do Cliente 6 corresponder ao mesmo horário para carregamento na Central 1 (11:00h) que o Cliente 8, o que impede que os dois clientes sejam atendidos pelas mesma central, já que a soma das quantidades dos pedidos ultrapassam a capacidade de carregamento naquele período naquela central. Com isso, o pedido do Cliente 8 que possui uma margem de contribuição menor do que a margem do total dos pedidos do Cliente 6, é direcionado à outra central para a otimização da margem de contribuição do sistema como um todo, algo que alguns sistemas utilizados por empresas não proporcionam; os mesmos apenas indicam a violação da capacidade, mas não sugerem uma solução, cabendo ao operador decidir, manualmente, quais pedidos remanejar entre centrais de modo a buscar atender toda a demanda de modo a maximizar a margem de contribuição líquida.

\section{Base de dados}

\begin{tabular}{c|c|c} 
Dados das Centrais dosadoras de concreto \\
\hline Central & $\begin{array}{c}\text { Capacidade de } \\
\text { carregamento por } \\
\text { período (em } \\
\text { caminhôes) }\end{array}$ & $\begin{array}{c}\text { Quantidade de } \\
\text { caminhóes } \\
\text { disponiveis }\end{array}$ \\
\hline \hline 1 & 3 & 20 \\
2 & 3 & 30 \\
3 & 3 & 35 \\
4 & 3 & 25
\end{tabular}

\begin{tabular}{|c|c|c|c|c|c|c|c|c|c|}
\hline Cliente & $\begin{array}{l}\text { Tempo de } \\
\text { viagem } \\
\text { Central } 1\end{array}$ & \begin{tabular}{|c|} 
Margem de \\
contribuição \\
Central 1
\end{tabular} & $\begin{array}{l}\text { Tempo de } \\
\text { viagem } \\
\text { Central } 2\end{array}$ & $\begin{array}{l}\text { Margem de } \\
\text { contribuiçãa } \\
\text { Central } 2\end{array}$ & $\begin{array}{l}\text { Tempo de } \\
\text { viagem } \\
\text { Central } 3\end{array}$ & $\begin{array}{c}\text { Margem de } \\
\text { contribuição } \\
\text { Central } 3\end{array}$ & $\begin{array}{l}\text { Tempo de } \\
\text { viagem } \\
\text { Central } 4\end{array}$ & $\begin{array}{l}\text { Margem de } \\
\text { contribuiçãa } \\
\text { Central } 4\end{array}$ & $\begin{array}{c}\text { Tempo de } \\
\text { descarregamento no } \\
\text { cliente }\end{array}$ \\
\hline Cliente 1 & "00:09:00 & $\$ 13$ & "00:25:00 & $\$ 12$ & $\begin{array}{l}00: 31: 00 \\
\end{array}$ & $\$ 11$ & $\begin{array}{l}00: 45: 00 \\
\end{array}$ & $\$ 10$ & 00:35:00 \\
\hline Cliente 2 & 01:15:00 & $\$ 9$ & $00: 45: 00$ & $\$ 11$ & 01:20:00 & $\$ 8$ & 01:25:00 & $\$ 7$ & 00:30:00 \\
\hline Cliente 3 & 00:29:00 & $\$ 9$ & 01:05:00 & $\$ 8$ & 00:20:00 & $\$ 10$ & 00:37:00 & $\$ 9$ & 00:25:00 \\
\hline Cliente 4 & 00:55:00 & $\$ 5$ & 00:32:00 & $\$ 9$ & 00:24:00 & $\$ 11$ & 00:10:00 & $\$ 12$ & 00:30:00 \\
\hline Cliente 5 & 00:15:00 & $\$ 13$ & 00:25:00 & $\$ 12$ & 00:33:00 & $\$ 11$ & 00:52:00 & $\$ 9$ & 00:40:00 \\
\hline Cliente 6 & 00:36:00 & $\$ 14$ & 00:21:00 & $\$ 15$ & 00:43:00 & $\$ 10$ & 00:57:00 & $\$ 8$ & 00:25:00 \\
\hline Cliente 7 & 00:39:00 & $\$ 16$ & 00:25:00 & $\$ 12$ & 00:31:00 & $\$ 11$ & 00:45:00 & $\$ 10$ & 00:35:00 \\
\hline Cliente 8 & 01:15:00 & $\$ 9$ & $00: 45: 00$ & $\$ 11$ & 01:20:00 & $\$ 8$ & 01:25:00 & $\$ 7$ & 00:30:00 \\
\hline Cliente 9 & 00:29:00 & $\$ 9$ & 01:05:00 & $\$ 8$ & $00: 25: 00$ & $\$ 10$ & 00:37:00 & $\$ 9$ & 00:25:00 \\
\hline Cliente 10 & $00: 55: 00$ & $\$ 5$ & 00:32:00 & $\$ 9$ & 00:24:00 & $\$ 11$ & 00:10:00 & $\$ 12$ & 00:30:00 \\
\hline
\end{tabular}

Figura 11 - Entrada de dados na base de dados

- exemplo aplicação do modelo à um caso real 
Programação de carregamento e entrega

\begin{tabular}{|c|c|c|c|c|c|c|c|c|c|c|c|}
\hline Pedidos & Cliente & $\begin{array}{l}\text { Horário de } \\
\text { recebimento }\end{array}$ & $\begin{array}{c}\text { Necessidade } \\
\text { de concreto } \\
\text { (em toneladas) }\end{array}$ & $\begin{array}{l}\text { Total do } \\
\text { pedido em } \\
\text { caminhões }\end{array}$ & $\begin{array}{c}\text { Central que } \\
\text { atenderáo } \\
\text { pedido }\end{array}$ & \begin{tabular}{|c|} 
Margem de \\
contribuição \\
esperada
\end{tabular} & $\begin{array}{c}\text { Horário de } \\
\text { carregamento } \\
\text { na Central }\end{array}$ & $\begin{array}{c}\text { Horário previsto } \\
\text { de retorno à } \\
\text { Central }\end{array}$ & $\begin{array}{c}\text { Status do } \\
\text { pedido }\end{array}$ & $\begin{array}{c}\text { Horário foi } \\
\text { ajustado? }\end{array}$ & $\begin{array}{l}\text { Quanto } \\
\text { tempo? }\end{array}$ \\
\hline 1 & Cliente 1 & $07: 25$ & 14 & 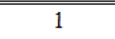 & 1 & $\$ 13$ & $07: 00$ & $08: 30$ & Confirmado & Não & - \\
\hline 2 & Cliente 1 & $07: 40$ & 36 & 2 & 1 & $\$ 26$ & $07: 30$ & $08: 30$ & Confirmado & Não & - \\
\hline 3 & Cliente 2 & 08:00 & 80 & 4 & 2 & $\$ 44$ & $07: 00$ & 09:30 & Confirmado & Não & - \\
\hline 4 & Cliente 2 & $08: 30$ & 52 & 3 & 2 & $\$ 33$ & $07: 30$ & $10: 00$ & Confirmado & Não & - \\
\hline 5 & Cliente 3 & 08:00 & 50 & 3 & 3 & $\$ 30$ & $07: 30$ & 09:00 & Confirmado & Não & - \\
\hline 6 & Cliente 4 & 08:00 & 38 & 2 & 4 & $\$ 24$ & $07: 30$ & 09:00 & Confirmado & Não & - \\
\hline 7 & Cliente 4 & $08: 15$ & 14 & 1 & 4 & $\$ 12$ & $07: 00$ & 09:30 & Confirmado & Sim & $00: 30$ \\
\hline 8 & Cliente 4 & $09: 55$ & 72 & 4 & 4 & $\$ 48$ & 09:00 & $11: 00$ & Confirmado & Não & - \\
\hline 9 & Cliente 4 & $10: 00$ & 58 & 3 & 4 & $\$ 36$ & $08: 30$ & $11: 00$ & Confirmado & Sim & $00: 30$ \\
\hline 10 & Cliente 4 & $10: 00$ & 10 & 1 & 4 & $\$ 12$ & $08: 30$ & $11: 00$ & Confirmado & Sim & $00: 30$ \\
\hline 11 & Cliente 5 & $10: 00$ & 17 & 1 & 1 & $\$ 13$ & $09: 30$ & $11: 00$ & Confirmado & Não & - \\
\hline 12 & Cliente 5 & $10: 05$ & 29 & 2 & 1 & $\$ 26$ & $09: 30$ & $11: 00$ & Confirmado & Não & - \\
\hline 13 & Cliente 6 & $11: 00$ & 24 & 2 & 2 & $\$ 30$ & $10: 30$ & $12: 00$ & Confirmado & Não & - \\
\hline 14 & Cliente 6 & $11: 00$ & 17 & 1 & 2 & $\$ 15$ & $10: 30$ & $12: 00$ & Confirmado & Não & - \\
\hline 15 & Cliente 6 & $11: 40$ & 48 & 3 & 2 & $\$ 45$ & $11: 00$ & $12: 30$ & Confirmado & Não & - \\
\hline 16 & Cliente 6 & $12: 00$ & 72 & 4 & 2 & $\$ 60$ & $11: 30$ & $13: 00$ & Confirmado & Não & - \\
\hline 17 & Cliente 7 & $10: 00$ & 70 & 4 & 1 & $\$ 64$ & 09:00 & $11: 30$ & Confirmado & Não & - \\
\hline 18 & Cliente 7 & $10: 00$ & 70 & 4 & 1 & $\$ 64$ & $08: 30$ & $11: 30$ & Confirmado & Sim & $00: 30$ \\
\hline 19 & Cliente 7 & $10: 00$ & 38 & 2 & 1 & $\$ 32$ & 08:00 & $11: 30$ & Confirmado & Sim & 01:00 \\
\hline 20 & Cliente 8 & $12: 00$ & 50 & 3 & 1 & $\$ 9$ & $11: 30$ & $13: 00$ & Confirmado & Não & - \\
\hline 21 & Cliente 9 & 13:00 & 10 & 1 & 3 & $\$ 10$ & $12: 30$ & $14: 00$ & Confirmado & Não & - \\
\hline 22 & Cliente 9 & $14: 00$ & 38 & 2 & 3 & $\$ 20$ & $13: 30$ & $15: 00$ & Confirmado & Não & - \\
\hline 23 & Cliente 10 & $14: 20$ & 38 & 2 & 4 & $\$ 12$ & $13: 30$ & $15: 30$ & Confirmado & Não & - \\
\hline
\end{tabular}

\section{Figura 12 - Tabela Resultado - Base de pedidos programados - exemplo aplicação do modelo à um caso real}

A programação obtida pelo SAD descrito neste trabalho foi a mesma que a obtida pela empresa utilizando o seu sistema corporativo, para o mesmo conjunto de dados. Vale ressaltar que o sistema utilizado hoje na Grande São Paulo pela empresa considera em sua estrutura restrições que não estão contempladas no SAD proposto. Entre elas, destacam as restrições de circulação de caminhões em algumas regiões e vias estruturais, além das restrições de rodízio de acordo com o dígito final placas dos veículos. Tais restrições, que foram tornadas inativas a fim de possibilitar a comparação de resultados, podem, no entanto, ser consideradas no SAD proposto, sem maiores dificuldades, sendo mais um problema de caracterização dos dados de entrada do que uma dificuldade do modelo matemático proposto. 


\section{Conclusão}

Este trabalho abordou o problema de programação de entrega do concreto dosado em centrais, com a finalidade de otimizar o resultado de receita marginal do sistema como um todo. Para tanto, o mesmo foi tratado como um problema de fluxo em rede e, baseada nesta rede, foi apresentada uma formulação matemática, a qual garante o atendimento das demandas dos clientes com o maior valor de receita marginal possível, respeitando as restrições de capacidade de carregamento em cada central, disponibilidade da frota e garantia de atendimento de todos os pedidos de cada cliente por uma única central.

A implementação do modelo proposto em ambiente de planilha contou com a utilização do programa Microsoft Excel, para conter a base de dados, em interação com o software de otimização Solver. Buscou-se, dessa forma, facilitar a entrada de dados e a compreensão dos resultados finais pelos usuários do modelo, que não necessitam ter conhecimento prévio de pesquisa operacional ou modelagem matemática, uma vez que a construção do modelo é totalmente automatizada e transparente para os usuários.

A aplicação prática realizada com dados reais de uma empresa comprovou que o modelo proposto atinge a solução ótima em tempos de processamento reduzidos. Sua facilidade de implantação e utilização torna o SAD proposto potencialmente útil para empresas de menor porte, que não tem recursos para investir num sistema corporativo, ou mesmo para conjuntos de centrais menores, localizadas em regiões cuja demanda não justifica o investimento para o desenvolvimento e a implantação de um sistema corporativo.

A flexibilidade do modelo em face à incorporação de diferentes restrições e o desenvolvimento de uma interface amigável para o usuário e a clareza de compreensão dos resultados são as grandes contribuições deste trabalho, apresentando uma ferramenta que poderá efetivamente ser utilizada para o aumento da eficiência das operações logísticas na entrega de concreto.

Embora pouco comum, uma das possíveis extensões para a continuidade desta pesquisa seria considerar a possibilidade de haver remanejamento da frota de caminhões betoneiras entre centrais, para que a central que estivesse com frota ociosa pudesse servir à central que estivesse com falta de disponibilidade de caminhões para carregamento. 
Outra possibilidade interessante consiste em contemplar a otimização com simulação em conjunto. Dessa forma, poderia se considerar um cancelamento aleatório de pedidos de tal forma que pudesse ser percebido o impacto da alteração no resultado da otimização.

\section{Referências}

Ahuja, R. K., Magnanti, T. L. e Orlin, J. B. (1993) Network flows: theory, algorithms and applications, Prentice Hall, NJ.

Anson, M., Tang, S. L., Ying, Y.C. e Lu, M. (2003) A practical simulation solution to planning concrete plant operations in Hong Kong. Journal of Construction Engineering and Management, vol. 129, pp. 547-554.

Côrtes, C. S. (2011) Modelo de decisão para a programação de entrega de concreto produzido em centrais. Dissertação (Mestrado) - Escola Politécnica da Universidade de São Paulo, Programa de Pós-Graduação em Engenharia de Sistemas Logísticos. São Paulo.

Durbin, M. T. (2003) The dance of the thirty-ton trucks: demand dispatching in a dynamic environment. PhD thesis, George Mason University.

Feng C., Cheng, T. e Wu, H. (2004) Optimizing the schedule of dispatching RMC trucks through genetic algorithms, Automation in Construction, vol. 13, pp. 327-340.

Hoffman K. e Durbin M. T. (2008) The dance of the thirty-ton trucks: dispatching and scheduling in a dynamic environment, Journal of Operations Research, vol. 56, pp. 3-19.

Matsatsinis N. (2004) Towards a decision support system for the ready concrete distribution system: A case of a greek company, European Journal of Operational Research, vol. 152, 487-499.

Mehta, P. K. e Monteiro, P. J. M. (1994) Concreto: estrutura, propriedades e materiais. São Paulo, Pini, 573 p.

Pandolfi, M. (1999) Alocação de veículos a centros de distribuição segundo critérios de margem de contribuição unitária e produtividade. Dissertação (Mestrado) - Escola Politécnica da Universidade de São Paulo, Programa de Pós-Graduação em Engenharia de Transportes, São Paulo.

Seref, M. H., Ahuja, R. e Winston, W. (2007) Developing spreadsheet-based decision support Systems, Dynamic Ideas.

SINIC - Sindicato Nacional da Indústria do Cimento (2011) Relatório anual 2011. São Paulo. Disponível em: <http://www.snic.org.br>. Acesso em: julho de 2011.

Tommelein I. e Li A. (1999) Just-in-time concrete delivery: mapping alternatives for vertical supply chain integration, in: Seventh Annual Conference of the International Group for Lean Construction, pp. 97-108. 
Wang, S.Q., Téo, C.L., Ofori, G. (2001) Scheduling the truckmixer arrival for a ready mixed concrete pour via simulation with risk. Journal of Construction Research, vol. 2, pp. 169179.

Yan S. e Lai W. (2007), An optimal scheduling model for ready mixed concrete supply with overtime considerations, Automation in Construction, vol. 16, pp. 734-744.

Yan S. e Lai W. (2008) Production scheduling and truck dispatching of ready mixed concrete, Transportation Research Part E, vol. 44, pp. 164-179.

Zayed, T. M. e Halpin, D. W. (2001) Simulation of concrete batch plant production. Journal of Construction Engineering and Management, vol. 127, n. 2, pp. 132-141. 